\title{
Dynamic Pricing in Cloud Manufacturing Systems under Combined Effects of Consumer Structure, Negotiation, and Demand
}

\author{
Wei Peng, Wei Guo, Lei Wang, and Ruo-Yu Liang \\ Key Laboratory of Mechanism Theory and Equipment Design of Ministry of Education, Tianjin University, Tianjin 300354, China \\ Correspondence should be addressed to Lei Wang; tjuwl@tju.edu.cn
}

Received 10 August 2016; Accepted 12 January 2017; Published 22 February 2017

Academic Editor: Vladimir Turetsky

Copyright @ 2017 Wei Peng et al. This is an open access article distributed under the Creative Commons Attribution License, which permits unrestricted use, distribution, and reproduction in any medium, provided the original work is properly cited.

In this study, we proposed a game-theory based framework to model the dynamic pricing process in the cloud manufacturing (CMfg) system. We considered a service provider (SP), a broker agent (BA), and a dynamic service demander (SD) population that is composed of price takers and bargainers in this study. The pricing processes under linear demand and constant elasticity demand were modeled, respectively. The combined effects of SD population structure, negotiation, and demand forms on the SP's and the BA's equilibrium prices and expected revenues were examined. We found that the SP's optimal wholesale price, the BA's optimal reservation price, and posted price all increase with the proportion of price takers under linear demand but decrease with it under constant elasticity demand. We also found that the BA's optimal reservation price increases with bargainers' power no matter under what kind of demand. Through analyzing the participants' revenues, we showed that a dynamic SD population with a high ratio of price takers would benefit the SP and the BA.

\section{Introduction}

The emergence of cloud manufacturing (CMfg) enables manufacturing capacities and resources to be traded in the form of service in a cloud environment. With the support of CMfg technology, service users are able to purchase manufacturing services from service markets on demand [1]. User participation in manufacturing service transaction is closely associated with service prices. Due to the enrichment of service resources, the use of cloud services is highly pricesensitive. Consequently, an appropriate price would make a seller more competitive and assist her in gaining higher revenue. But the fixed price which is currently adopted by most cloud providers impedes the efficient allocation of service resources in a dynamic environment [2]. With the growing of manufacturing service transactions in the cloud environment, the issue of how to dynamically determine service prices to maximize the revenues is becoming increasingly critical for service sellers.

In a CMfg system, three types of roles are involved in service transaction: service provider (SP), broker agent
(BA), and service demander (SD). SPs own service resources and provide BAs with them. SDs play the role of service buyers and they purchase services from BAs on demand. BAs are responsible for supply-demand matching and delivering services according to SDs' requirements [3]. In an ideal CMfg system, BAs are smart enough to deal with the service transaction and SDs do not need to know how and where the services are provided [3]. A certain number of SPs, BAs, and SDs constitute a manufacturing supply chain (MSC) [4] centering on service transaction.

Compared to traditional supply chain, the MSC in a CMfg system has much enhanced flexibility and capability [4]. These characteristics enable the MSC to serve a broad dynamic population consisting of heterogeneous SDs. In general, the SD population includes two types of users: price takers and bargainers. A price taker purchases service at a posted price, but a bargainer negotiates with BAs to strive for a lower price. The role-differentiated behavior of SDs increases the complexity of service pricing in a CMfg system. Thus SD population structure and user negotiation behavior should be considered in selection of service prices. 
Another factor that is directly related to price policy in a cloud environment is the demand form. The diversity of SDs induces substantial differences in demand forms. Some SDs have fixed demand, while some others might have pricesensitive demand. Researchers have proposed different kinds of demand functions to model consumer demand in cloud service markets, such as stochastic demand function [5], linear demand function [6], and constant elasticity demand function [7]. The significant impacts of demand forms on pricing strategy have been validated in the field of supply chain [8].

In a cloud environment, these factors work together to influence the service prices. Such a complicated situation poses a conundrum for SPs and BAs attempting to determine their optimal prices to gain higher profits. Unfortunately, there has been a lack of study analyzing how SD population structure (i.e., the relative proportions of price takers and bargainers), negotiation behavior, and demand forms jointly affect service pricing in a cloud environment. Therefore, this paper attempts to fill this research gap by incorporating two types of demand (linear demand and constant elasticity demand) and a dynamic SD population consisting of price takers and bargainers into the analysis of dynamic pricing in a CMfg system. Our goal is to investigate the combined effects of SD population structure, negotiation, and demand forms on SPs' and BAs' pricing strategies and thereby contribute to the development of pricing mechanism in CMfg systems.

In this paper, we employ a game-theory based framework to model the dynamic pricing problem in MSC consisting of SP, BA, and dynamic SD population. Within this framework the SP leads the game and chooses the wholesale price and the BA (follower) determines the posted price and reservation price. The SD population is composed of price takers and bargainers. Price takers purchase services at the posted price. Bargainers negotiate with the BA in order to obtain a better price. Whether a bargainer deals with the BA depends on each other's reservation prices (or valuations) and bargaining power. The BA only knows the probability distribution of the bargainers' valuations. We model the negotiation outcome with generalized Nash bargaining solution (GNBS). To examine the combined effects of SD population structure, negotiation, and demand forms on SP's and BA's pricing strategies, the dynamic pricing processes under linear demand and constant elasticity demand are modeled, respectively.

Our main contribution is to show how the impacts of SD population structure and negotiation on SP's and BA's equilibrium prices and expected revenues depend on different demand models in a CMfg system with a dynamic $\mathrm{SD}$ population. We make comparisons of the influences of SD population structure on equilibrium prices when the SP and the BA face linear demand and constant elasticity demand. We show that the optimal wholesale price, BA's optimal reservation price, and posted price all increase with the proportion of price takers under linear demand but decrease with it under constant elasticity demand. Furthermore, we examine the effect of bargaining power on equilibrium prices under linear demand and constant elasticity demand. We found that BA's optimal reservation price increases with bargainers' power no matter under what kind of demand.
But BA's posted price only rises with bargainers' power in two situations: under a linear demand with a large pricesensitivity index and under a constant elasticity demand with a small price-elasticity index. And the wholesale price rises with bargainers' power except under a constant elasticity demand with a relative large price-elasticity index. Through analyzing the participants' revenues, we found that a dynamic SD population with a high ratio of price takers would benefit the SP and the BA. We also found that the rise of the bargainers' power diminishes BA's expected revenue. However, the SP can benefit from raising the wholesale price with increasing bargainers' power under a constant elasticity demand with a relative small price-elasticity index.

The remaining part of the paper proceeds as follows: Section 2 reviews the related literature. Section 3 describes the pricing models and associated propositions. In Section 4 we use a numeric study to analyze the combined impacts of SD population structure, negotiation, and demand forms on equilibrium prices. Section 5 summarizes the main conclusions and discusses the managerial implications and limitations.

\section{Literature Review}

Dynamic pricing has consequently been a focus of cloud service transaction. A considerable amount of dynamic pricing models has been proposed in recent years, such as game-theoretic model [9-12], auction-based model [13], autonomic model [2], network utility maximization model [14], stochastic dynamic programming model $[5,15]$, genetic model [16], and financial option model [17]. More detailed classification can be found in [18]. We follow the first stream of research and use game theory to model the dynamic pricing problem in a CMfg system. Game-theoretic models focus on price competition among vendors. Researchers have studied this problem from several perspectives, including horizontal competition (e.g., [9, 12]), vertical competition (e.g., [19]), and hybrid competition (e.g., [20]) in cloud environment. Our study also concentrates on vertical competition. However, the above literature has potentially assumed that all the SDs are price takers. In fact, bargainers occupy a considerable proportion of the SD population in cloud environment. The application of information technology enables them to negotiate with vendors at a very low cost. Nevertheless, bargaining behavior was mainly considered in the research of negotiation mechanism design (e.g., [21, 22]). The focuses of these studies are on negotiation protocols rather than pricing strategies.

The most relevant studies were conducted in the field of supply chain management. Gill and Thanassoulis [23, 24] explored the impact of bargainers on firms' pricing strategies by using the Hotelling model. They found that a rise in the proportion of bargainers would induce an increase in firms' posted prices and a decrease in consumers' surplus. But in their models the firms make all the offers and the size of consumer population is unchanged, which restrict its application. Kuo et al. [25] built a leader-follower-game model and studied the impacts of consumer structure and 
bargaining power on equilibrium prices in a supply chain containing a manufacturer, a retailer, and some customers. They showed that the retailer's posted price and cut-off price increase with the proportion of the bargainers and bargainers' power. In another paper, Kuo et al. [26] studied the effect of negotiation on the pricing strategy of a retailer with limited inventory. They found that the retailer's benefit increases with the proportion of bargainers and her own bargaining power. However, these conclusions were derived under the assumption that the consumer population is fixed and the demand function is linear. Whether these valuable findings remain valid when the consumer population is dynamic and how demand forms, SD population structure, and negotiation affect equilibrium prices jointly in cloud environment are still unclear.

Our research is different from these studies in several key ways. First, we model the pricing problem in a CMfg system with a dynamic SD population. Second, we introduce linear and constant elasticity demand into our pricing models. Third, we explore the combined effects of SD population structure, negotiation, and demand forms on SP's and BA's equilibrium prices and expected revenues.

\section{Pricing Model}

Consider MSC consisting of monopoly SP that provides a kind of services, a BA, and a dynamic SD population which depends on demand. The SP sells services to the BA at a wholesale price, and the BA sells services to two types of SDs: price takers and bargainers. A price taker purchases services at a posted price. But a bargainer negotiates with the BA and seeks to purchase services at a price lower than the posted price. Each bargainer has a valuation of the services needed and refuses any offer higher than this appraisement. To protect its profit, the BA sets a reservation price which is the lowest price it can accept. If a bargainer failed to reach an agreement with the BA, she will quit the transaction. The $\mathrm{BA}$ as well as the bargainer will incur a bargaining cost in the negotiation.

Both the SP and the BA seek to maximize their expected revenues through choosing the optimal prices. The SP sets the wholesale price first, and the BA decides on the posted price and reservation price after observing SP's decision. They are all rational participants and have the same knowledge about the market information. This is a two-stage leader-follower game. The SP and the BA play the role of leader and follower, respectively. The leader will consider the follower's response when setting the wholesale price. The capacity constraint of the SP is not considered in this study.

In service pricing process, the SDs' demand is necessary for the SP and the BA. Most of the literature on cloud service pricing used certain functions (e.g., $[12,27,28]$ ) or stochastic process (e.g., $[5,14,15])$ to describe consumer demand. Essentially, these approaches represent the inverse relationship between price and demand. Following the former stream of studies, we choose two widely used demand functions (linear demand and constant elasticity demand) to characterize the SDs' demand in this study. The total demand comes from price takers and bargainers. But the demand from bargainers is their initial demand as they may quit transactions. Using the initial demand is reasonable since this is the original information collected from the service market. More importantly, the BA and the SP could forecast bargainers' final demand only if they know their initial demand. Assume that the law of demand from price takers and the law of initial demand from bargainers are the same; then we can describe the total demand with a uniform function. The SP and the BA have knowledge of the demand function and the proportion of price takers (or bargainers). But they only know the probability distribution of the bargainers' valuations.

For computational simplicity, we assume that each SD purchases one unit of the services. Thus the demand equals the number of SDs. Next we analyze the SP's and the BA's pricing strategies under the two types of demand functions. The notations used in this study are listed in Abbreviations.

3.1. Pricing Model under Linear Demand. The linear demand function can be written as $d=d_{0}-\alpha p_{a}$. Assuming that there is no transaction cost for all the participants, the SP's expected revenue from indirectly trading with the price takers is

$$
U_{s}^{1}\left(p_{s}\right)=\beta\left(d_{0}-\alpha p_{a}\right)\left(p_{s}-c_{s}\right) .
$$

And the BA's expected revenue from trading with the price takers can be represented as follows:

$$
U_{a}^{1}\left(p_{a}\right)=\beta\left(d_{0}-\alpha p_{a}\right)\left(p_{a}-p_{s}\right) .
$$

But their profits from transacting with the bargainers depend on negotiation results. To model the outcome of the bargaining between a bargainer and the BA, the GNBS [29] which is a popular tool to model the negotiation between two participants [26] was employed in this study. In the negotiation between the BA and a bargainer, the BA's surplus is $p_{b}-p_{r a}\left(p_{r a} \geq p_{s}+c_{a}\right)$ and the bargainer's surplus is $p_{v}-c_{b}-p_{b}$. Given the bargainer's power, the optimal final price is

$$
p_{b}^{*}=\arg \max _{p_{r a} \leq p_{b} \leq \min \left\{p, p_{v}\right\}}\left(p_{v}-c_{b}-p_{b}\right)^{\gamma}\left(p_{b}-p_{r a}\right)^{1-\gamma},
$$

where $p_{v} \geq c_{b}+p_{b}$ and $p_{b} \geq p_{r a}$.

If $p_{v}<p_{r a}+c_{b}$, the BA would reject the transaction and the bargainer would quit. Quitting a transaction is very common in cloud environment, since SD could use local resources if she fails to reach the target price [9]. In other conditions, they could reach an agreement. The optimal solution, $(1-\gamma)\left(p_{v}-c_{b}\right)+\gamma p_{r a}$, can be obtained from the first derivative of (3) with respect to $p_{b}$. Thus the optimal final price is

$$
p_{b}^{*}=\min \left\{p_{a},(1-\gamma)\left(p_{v}-c_{b}\right)+\gamma p_{r a}\right\}
$$

According to (4), a bargainer with a valuation higher than $\left(p_{a}-\gamma p_{r a}+(1-\gamma) c_{b}\right) /(1-\gamma)$ will pay the posted price for the services. But if the bargainer's valuation is located in 
$\left[p_{r a}+c_{b},\left(p_{a}-\gamma p_{r a}+(1-\gamma) c_{b}\right) /(1-\gamma)\right]$, she will purchase the services at the price $(1-\gamma)\left(p_{v}-c_{b}\right)+\gamma p_{r a}$. Therefore,

$$
p_{b}^{*}= \begin{cases}p_{a} & \text { if } p_{v} \geq \frac{p_{a}-\gamma p_{r a}+(1-\gamma) c_{b}}{1-\gamma}, \\ (1-\gamma)\left(p_{v}-c_{b}\right)+\gamma p_{r a} & \text { if } p_{v} \in\left[p_{r a}+c_{b}, \frac{p_{a}-\gamma p_{r a}+(1-\gamma) c_{b}}{1-\gamma}\right] .\end{cases}
$$

Assuming that all the bargainers have the same bargaining power, the BA's expected revenue from trading with the bargainers can be written as

$$
\begin{aligned}
& U_{a}^{2}\left(p_{a}, p_{r a}\right)=(1-\beta)\left(d_{0}-\alpha p_{a}\right)\left(p_{a}-p_{s}-c_{a}\right) \\
& \cdot \bar{F}\left(\frac{p_{a}-\gamma p_{r a}+(1-\gamma) c_{b}}{1-\gamma}\right)+(1-\beta)\left(d_{0}-\alpha p_{a}\right) \\
& \cdot \int_{p_{r a}+c_{b}}^{\left(p_{a}-\gamma p_{r a}+(1-\gamma) c_{b}\right) /(1-\gamma)}\left[(1-\gamma)\left(x-c_{b}\right)+\gamma p_{r a}-p_{s}\right. \\
& \left.-c_{a}\right] f(x) d x .
\end{aligned}
$$

$$
\begin{aligned}
\left(p_{a}, p_{r a}\right) \in \arg \max _{p_{a}, p_{r a}} & U_{a}\left(p_{a}, p_{r a}\right) \\
= & \beta\left(d_{0}-\alpha p_{a}\right)\left(p_{a}-p_{s}\right)+(1-\beta)\left(d_{0}-\alpha p_{a}\right)\left(p_{a}-p_{s}-c_{a}\right) \bar{F}\left(\frac{p_{a}-\gamma p_{r a}+(1-\gamma) c_{b}}{1-\gamma}\right) \\
& +(1-\beta)\left(d_{0}-\alpha p_{a}\right) \int_{p_{r a}+c_{b}}^{\left(p_{a}-\gamma p_{r a}+(1-\gamma) c_{b}\right) /(1-\gamma)}\left[(1-\gamma)\left(x-c_{b}\right)+\gamma p_{r a}-p_{s}-c_{a}\right] f(x) d x,
\end{aligned}
$$

subject to $c_{a}+p_{s}-p_{r a} \leq 0$,

$$
\begin{aligned}
& p_{r a}-p_{a} \leq 0, \\
& p_{a}-h \leq 0 .
\end{aligned}
$$

The last constraint guarantees that there are always some bargainers that can reach an agreement with the BA.

3.2. Pricing Model under Constant Elasticity Demand. In this section, we characterize the pricing model under constant elasticity demand (the function can be written as $d=$ $\left.d_{0} p_{a}^{-\tau}\right)$. As the components are the same as those under linear
And the SP's expected revenue from indirectly trading with the bargainers is

$$
U_{s}^{2}\left(p_{s}\right)=(1-\beta)\left(p_{s}-c_{s}\right)\left(d_{0}-\alpha p_{a}\right) \bar{F}\left(p_{r a}+c_{b}\right) .
$$

Based on the analysis above, when price takers coexist with bargainers in the MSC, the price competition between the SP and the BA can be represented by the following twostage model:

$$
\begin{aligned}
\max _{p_{s}} & U_{s}\left(p_{s}\right) \\
& =\left(p_{s}-c_{s}\right)\left(d_{0}-\alpha p_{a}\right)\left[\beta+(1-\beta) \bar{F}\left(p_{r a}+c_{b}\right)\right],
\end{aligned}
$$

subject to $c_{s}-p_{s} \leq 0$,

where, for a given $p_{s}$, 
where, for a given $p_{s}$,

$$
\begin{aligned}
\left(p_{a}, p_{r a}\right) \in \arg \max _{p_{a}, p_{r a}} & U_{a}\left(p_{a}, p_{r a}\right) \\
= & \beta\left(p_{a}-p_{s}\right) d_{0} p_{a}^{-\tau}+(1-\beta)\left(p_{a}-p_{s}-c_{a}\right) d_{0} p_{a}^{-\tau} \bar{F}\left(\frac{p_{a}-\gamma p_{r a}+(1-\gamma) c_{b}}{1-\gamma}\right) \\
& +(1-\beta) d_{0} p_{a}^{-\tau} \int_{p_{r a}+c_{b}}^{\left(p_{a}-\gamma p_{r a}+(1-\gamma) c_{b}\right) /(1-\gamma)}\left[(1-\gamma)\left(x-c_{b}\right)+\gamma p_{r a}-p_{s}-c_{a}\right] f(x) d x,
\end{aligned}
$$

subject to

$$
\begin{aligned}
& c_{a}+p_{s}-p_{r a} \leq 0, \\
& p_{r a}-p_{a} \leq 0, \\
& p_{a}-h \leq 0 .
\end{aligned}
$$

In the two-stage price game between the SP and the BA, their optimal strategies form a subgame perfect Nash equilibrium (SPNE). To obtain the SPNE of (8) and (10), we first analyze the existence and uniqueness of the follower's optimal strategy for a given wholesale price.

3.3. Existence and Uniqueness of the Follower's Optimal Strategy. In this subsection, we show that (8) and (10) have unique equilibrium in the feasible zone under some constraints. To simplify the analysis, we have the following assumption.

Assumption 1. The cumulative distribution function, $F(\cdot)$, is uniformly distributed on $[0, h]$.

Consequently, $f(\cdot)=1 / h$ and $F(\cdot)$ have an increasing failure rate. Under Assumption 1, the following propositions characterize the existence and uniqueness of the solutions that maximize the BA's expected revenue for a given wholesale price.

Proposition 2. Given the SP's wholesale price, there exists a unique pair of posted price and reservation price that maximize the BA's expected revenue under linear demand.

All proofs are in Appendix.

Proposition 3. Given the SP's wholesale price, there exists a unique pair of posted price and reservation price that maximize the BA's expected revenue under constant elasticity demand when the following conditions are satisfied:

(a) $\tau \geq \max \left\{1,2 h E_{1} /\left(E_{2}+E_{3}\right)\right\}$.

(b) $\tau \leq\left(p_{s}+c_{a}\right)\left[h-(1-\beta)\left(p_{s}+c_{a}+c_{b}\right)\right] / \beta h c_{a}$.

$E_{1}=(\beta-\gamma+\beta \gamma) h+(1-\beta) \gamma c_{a}-(1-\beta) c_{b}+(1-\beta) \gamma p_{s}$, $E_{2}=(1-\beta)(1-\gamma) c_{a}^{2}+2(1-\beta)\left[c_{b}-(1-\gamma)\left(h-p_{s}\right)\right] c_{a}$, and $E_{3}=\left(h-p_{s}\right)\left[(1+\beta-\gamma+\beta \gamma) h-2(1-\beta) c_{b}-(1-\beta)(1-\gamma) p_{s}\right]$.

Note that the price-elasticity index is restricted to a limited range. This is reasonable since a large price-elasticity index would lead to the participators' expected revenues approaching zero.
Propositions 2 and 3 show that the unique optimal solutions of the follower's expected revenue functions are guaranteed for any given wholesale price under some conditions. Since the SP has full knowledge of the BA's response, she is able to choose a wholesale price that maximizes her expected revenue.

\section{Numeric Analysis}

Due to the complication of the two pricing models, it is very challenging to obtain the analytic solutions of them. Therefore, we conducted a numeric study to explore the combined impacts of SD population structure, negotiation, and demand forms on the equilibrium prices.

The impacts of the demand functions on pricing strategies mainly depend on price-sensitivity and price-elasticity index; the SD population structure is reflected by the proportion of price takers (or bargainers), and the negotiation outcome relies on participants' bargaining power. Therefore, we considered these factors in this section and analyzed their combined effects on the SP's and the BA's optimal pricing strategies. To make the demand functions nontrivial, the upper bound of the bargainers' valuations, $h$, should be less than or equal to the upper bound of the posted price. For simplicity, we assume $h$ equals the upper bound of the posted price. Under linear demand, $h=d_{0} / \alpha$. And under constant elasticity demand, $h$ equals infinity in theory. However, this is unrealistic in practice. Thus we consider that if the demand is close enough to zero (we set the criterion as $d \leq 0.001$ ) for a given $\tau$, then the corresponding value of $p_{a}$ is the upper bound of the posted price. Other parameters were set as follows: $d_{0}=1000, c_{s}=10, c_{a}=5$, and $c_{b}=6$. We employed a particle swarm optimization (PSO) based algorithm [30] to solve the two models. The two constrained models were reduced to unconstrained models by using exterior penalty method. The main parameters used in the algorithm were set according to Rezaee Jordehi and Jasni's review [31]. In the following parts, we first investigated the impacts of price-sensitivity and price-elasticity index on the equilibrium prices and then explored how the SP's and the BA's optimal 


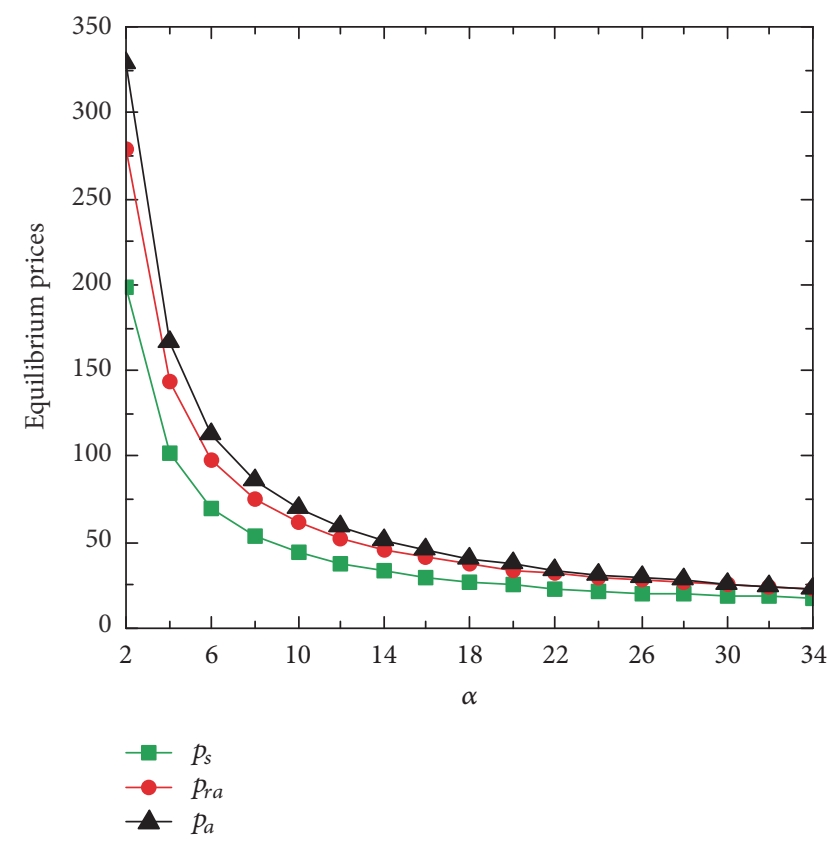

(a)

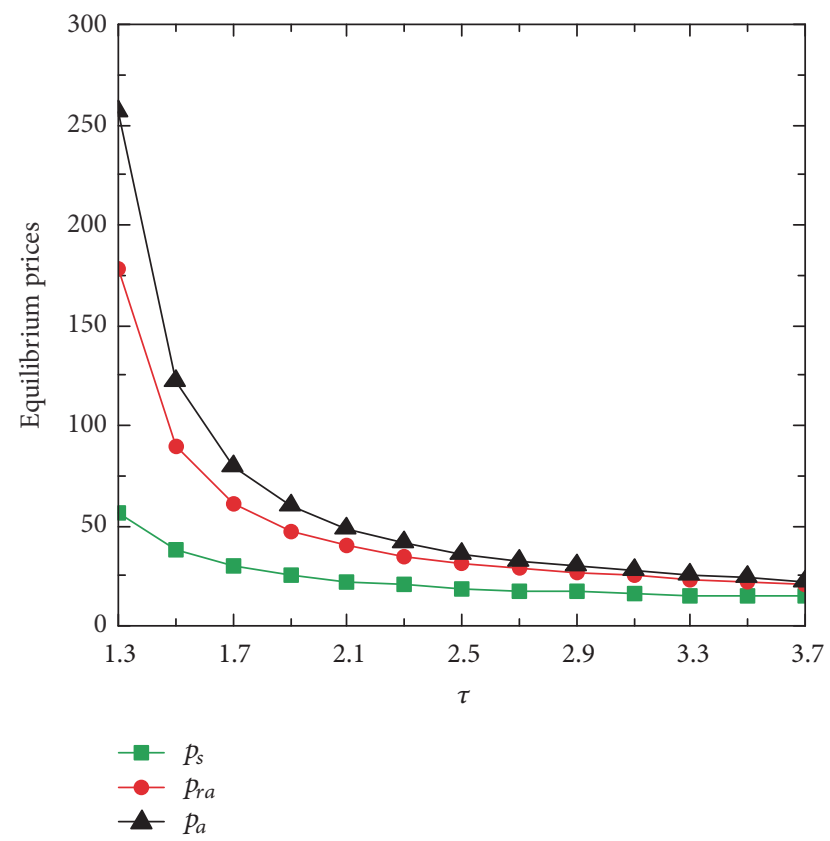

(b)

FIGURE 1: Effects of price-sensitivity and price-elasticity index on equilibrium prices. (a) Price-sensitivity and (b) price-elasticity index.

prices change under different combinations of SD population structure, bargaining power, and demand functions.

4.1. Effects of Price-Sensitivity and Price-Elasticity Index. Let $\alpha$ vary from 2 to 34 at intervals of 2 , and let $\tau$ vary from 1.3 to 3.7 at intervals of 0.2 . Figure 1 depicts the variations in the equilibrium prices.

As shown in Figure 1, all the equilibrium prices (i.e., $p_{s}^{*}$, $p_{r a}^{*}$, and $p_{a}^{*}$ ) decrease nonlinearly with $\alpha$ and $\tau$. The results are intuitive since a large $\alpha$ (or $\tau$ ) means a low upper bound of the posted price. Therefore, the equilibrium prices drop with $\alpha$ and $\tau$. Remark 4 characterizes the impacts of demand functions on equilibrium prices.

Remark 4. The wholesale price, the BA's reservation price, and posted price all decrease nonlinearly with pricesensitivity and price-elasticity index.

4.2. Combined Effects of Demand-Related Parameters and SD Population Structure. To explore whether the equilibrium prices are affected by the combined effects of demand functions and SD population structure, we analyzed the variations in the equilibrium prices with varying $\beta$ under different levels of $\alpha$ and $\tau$, respectively. Let $\beta$ vary from 0.1 to 0.9 at intervals of 0.1 . The results are portrayed in Figures 2 and 3 .

Figures 2 and 3 reveal that (1) $p_{a}^{*}, p_{r a}^{*}$, and $p_{s}^{*}$ all increase with $\beta$ under linear demand but decrease with $\beta$ under constant elasticity demand and (2) $U_{a}$ and $U_{s}$ go up with $\beta$ no matter under what kind of demand.

The first finding is partly consistent with the previous study on dynamic pricing in a supply chain with fixed consumer population [25], which found that the optimal posted price and cut-off price (reservation price) increase with the proportion of bargainers (i.e., $1-\beta$ ). This finding remains valid in the CMfg system when the SP and the BA are facing a constant elasticity demand. But under a linear demand, the equilibrium prices show the opposite behavior. The reason is that the value maximizing the BA's revenue from trading with price takers is higher than the value maximizing the BA's revenue from trading with bargainers under linear demand. Thus the optimal prices rise with the proportion of price takers. The second finding implies that both the SP's and the BA's profits are maximized when no bargainers exist. This finding differs from Gill and Thanassoulis [24] and Kuo et al.s [26] results demonstrating that the sellers' expected revenue increases with the proportion of bargainers. The rather contradictory results on this effect may be due to the difference of consumer population. When the number of consumers is fixed, not all members have needs for the products (services) for a given price. The sellers wish there would be more bargainers since the demand rises with the proportion of bargainers. But in our model, the demand is definite for a given posted price, which means that all the SDs have demand for the services. Consequently, the sellers benefit from the rising of the average price which goes up with the proportion of price takers. Remark 5 characterizes the variations in the SP's and the BA's equilibrium prices and expected revenues when SD population structure changes.

Remark 5. When the proportion of price takers increases,

(a) the optimal wholesale price, the BA's optimal reservation price, and posted price rise under linear demand but decrease under constant elasticity demand; 


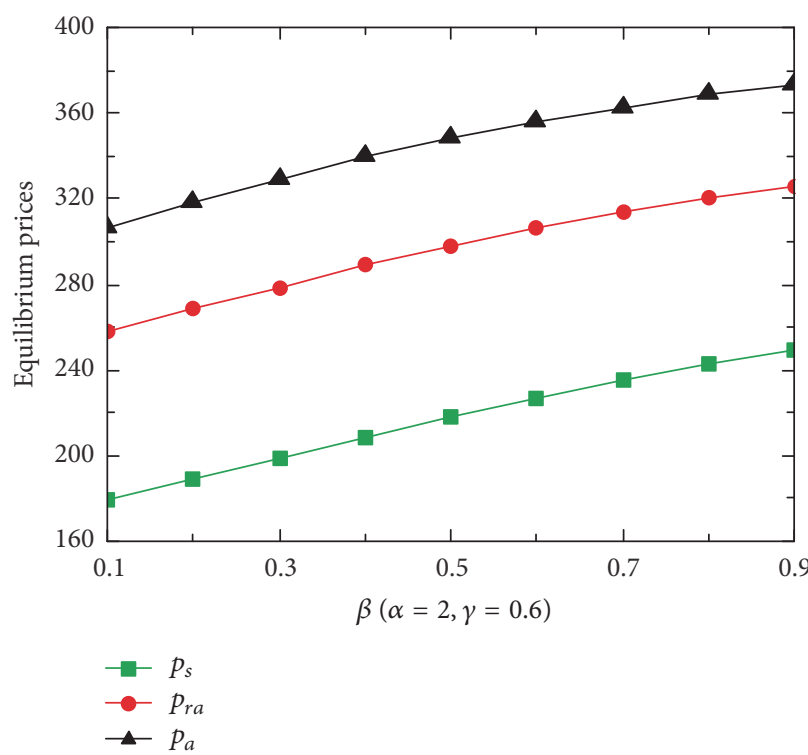

(a)

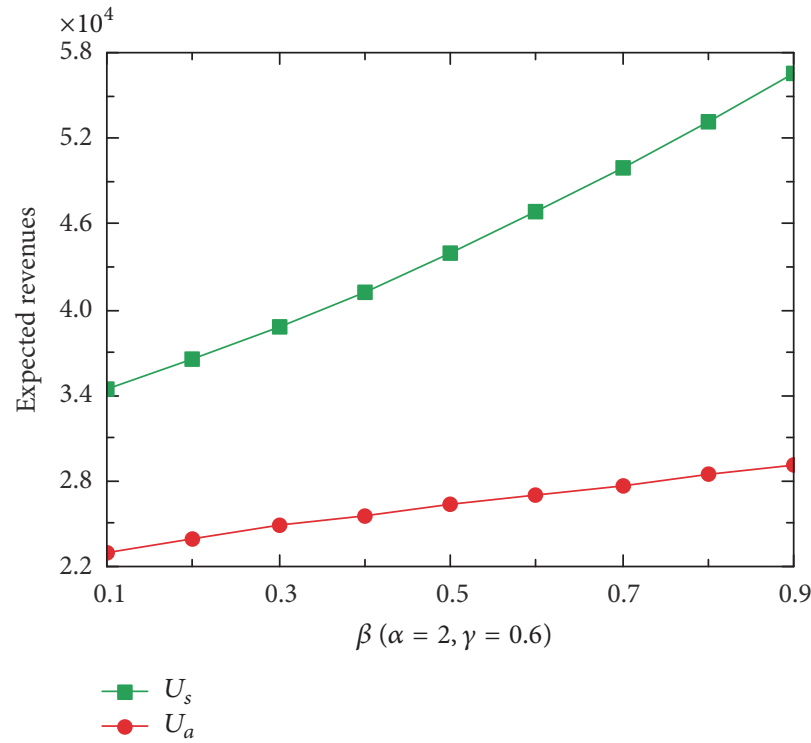

(c)

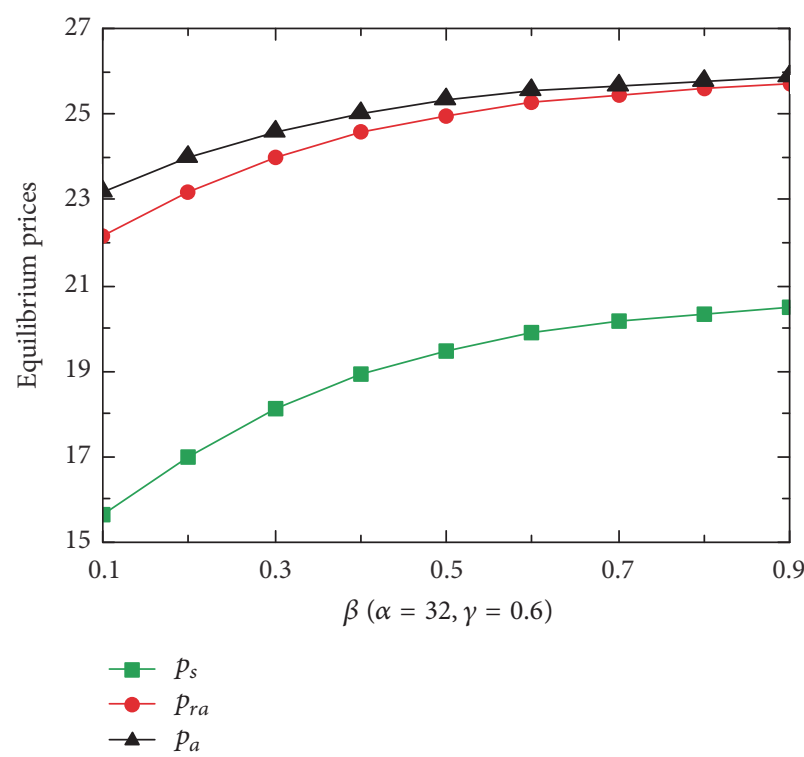

(b)

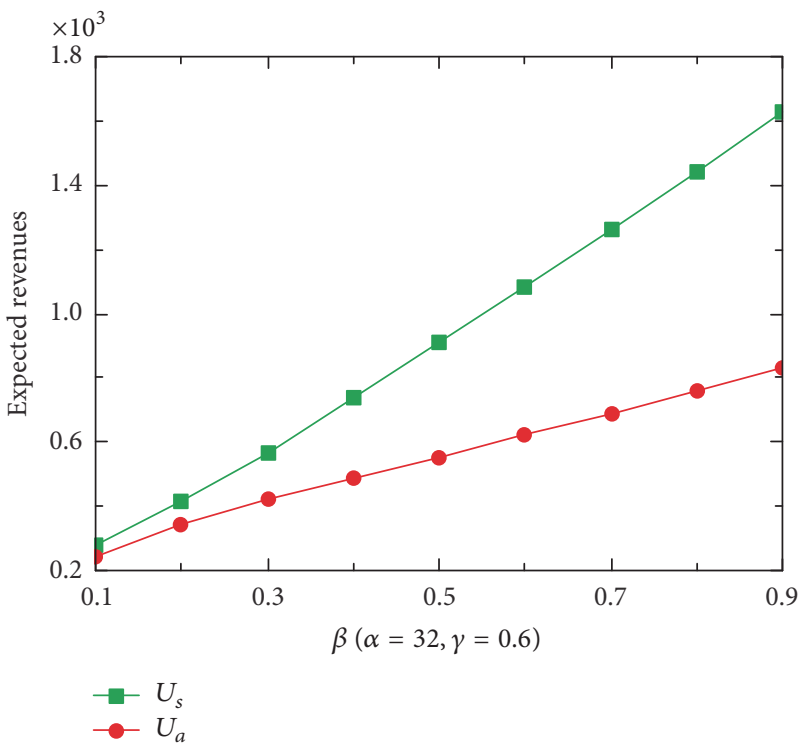

(d)

FIGURE 2: Combined effects of price-sensitivity and the proportion of price takers on SP's and BA's equilibrium prices and expected revenues. (a) $\alpha=2$ and $\gamma=0.6$, (b) $\alpha=32$ and $\gamma=0.6$, (c) $\alpha=2$ and $\gamma=0.6$, and (d) $\alpha=32$ and $\gamma=0.6$.

(b) the SP's and the BA's expected revenues go up no matter under what kind of demand.

4.3. Combined Effects of Demand-Related Parameters and Bargaining Power. We then analyzed the combined effects of demand-related parameters and bargainers' power on the SP's and the BA's equilibrium prices and expected revenues. Let $\gamma$ vary from 0.1 to 0.9 at intervals of 0.1 . The values of $\alpha$ and $\tau$ are the same as before. The results are depicted in Figures 4 and 5 .

Figures 4 and 5 show that (1) $p_{r a}^{*}$ increases with $\gamma$ no matter under what kind of demand; (2) the situation of a linear demand with large $\alpha$ and the situation of a constant elasticity demand with small $\tau$ lead $p_{a}^{*}$ to rise slightly with $\gamma$, while in other situations, $p_{a}^{*}$ declines with $\gamma$; (3) $p_{s}^{*}$ decreases with $\gamma$ in the situation of a constant elasticity demand with a large $\tau$; in other situations, it always increases with $\gamma$; and (4) $U_{a}$ always falls with $\gamma$, and $U_{s}$ also decreases with $\gamma$ except in the situation of a constant elasticity demand with a small $\tau$.

Kuo et al. [26] modeled the pricing process in a supply chain with fixed consumer population and found that the retailer's posted price drops with bargainers' power but the reservation price goes up with it. Our analysis demonstrates that such an insight into the seller's reservation price is robust in a cloud environment with dynamic consumer population. But the variation in the posted price is not fully consistent 


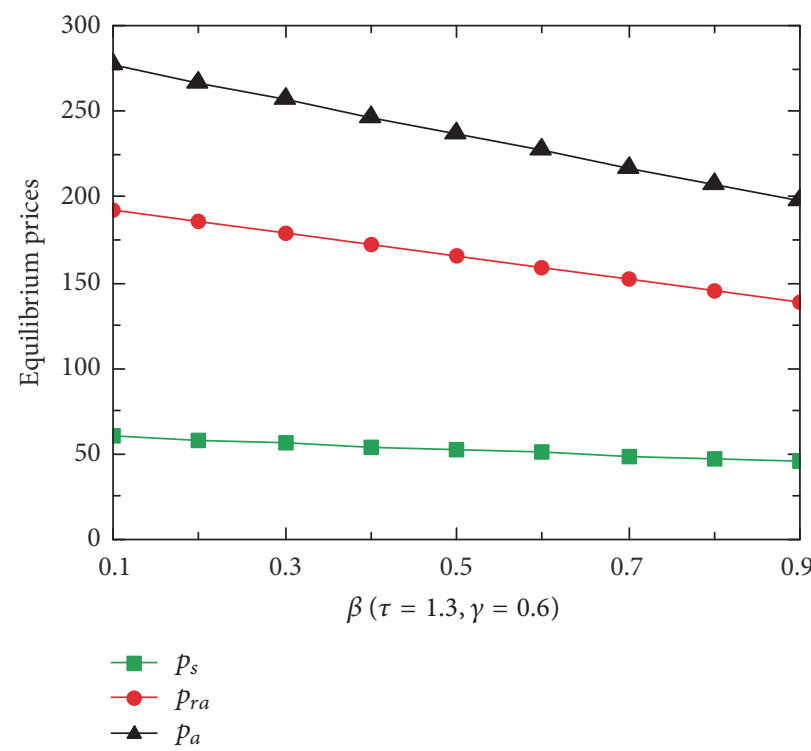

(a)

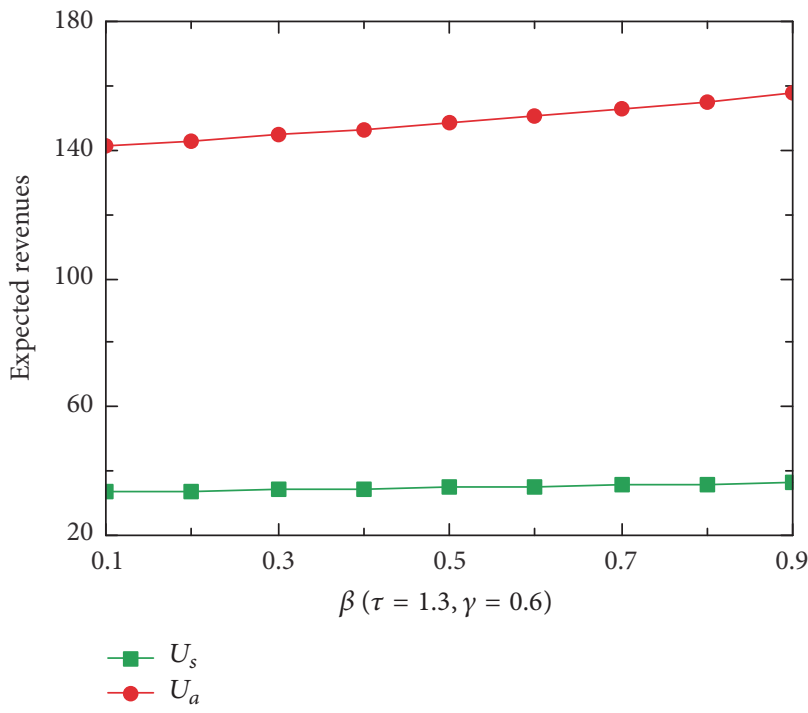

(c)

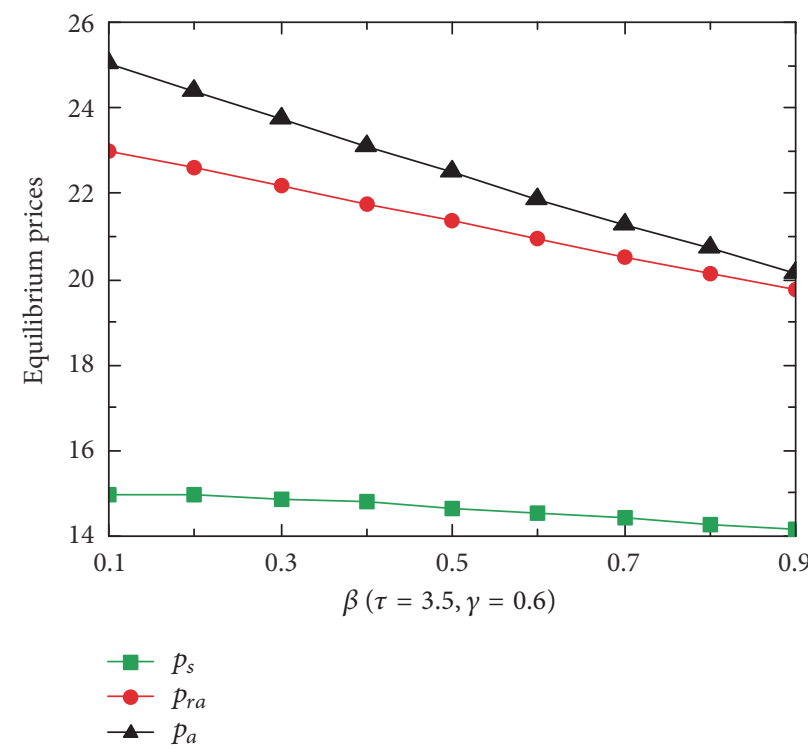

(b)

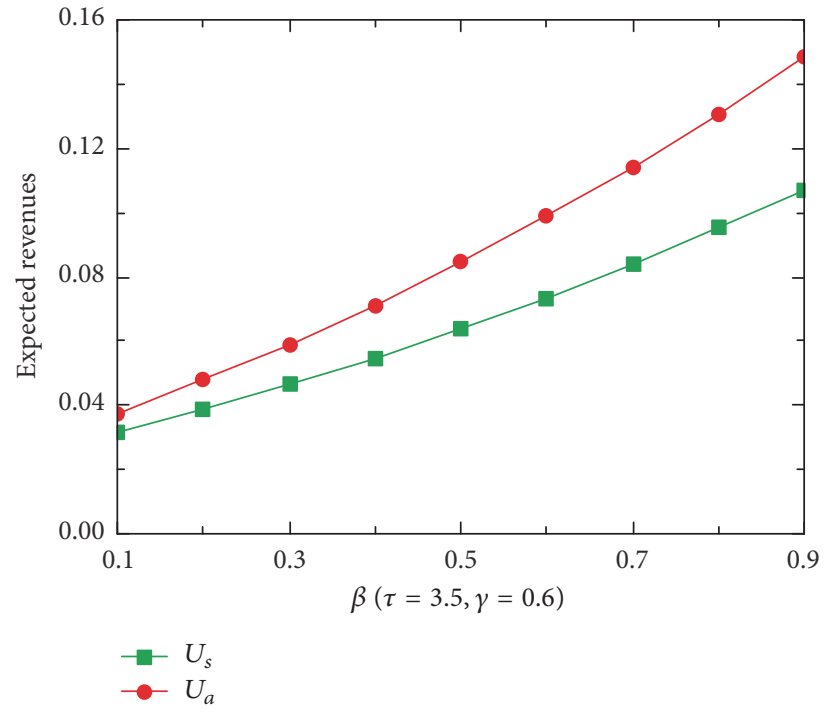

(d)

FIGURE 3: Combined effects of price-elasticity index and the proportion of price takers on SP's and BA's equilibrium prices and expected revenues. (a) $\tau=1.3$ and $\gamma=0.6$, (b) $\tau=3.5$ and $\gamma=0.6$, (c) $\tau=1.3$ and $\gamma=0.6$, and (d) $\tau=3.5$ and $\gamma=0.6$.

with their conclusion. In the situation of being under a linear demand with a large price-sensitivity index and in the situation of being under a constant elasticity demand with a small price-elasticity index, the posted price rises slightly with bargainers' power. A possible explanation for this result may be that the rise of the average price counteracts the loss from the decreased demand. The rise of the posted price leads to a decrease in the demand and a rise in the average price. But in this two situations, the demand changes slowly with the posted price. If the profit from the rise of the average price can neutralize the loss from the decreased demand, it is reasonable for the BA to raise the posted price.
The variation of the wholesale price might be related to the price-elasticity index. Since the demand is close to zero in the situation of a constant elasticity demand with a relative large price-elasticity index, a lower wholesale price is appropriate as it motivates the BA to lower the posted price in order to attract more SDs.

A powerful bargainer would force the final price down to a level close to the BA's reservation price. Besides, the increase of the BA's reservation price leads to a drop in total transactions. Consequently, the BA's expected revenue falls with the bargainers' power. The inconsistency in Figure 5(c) may be due to the fact that the profit from increased wholesale price can cover the loss from decreased demand in a situation 


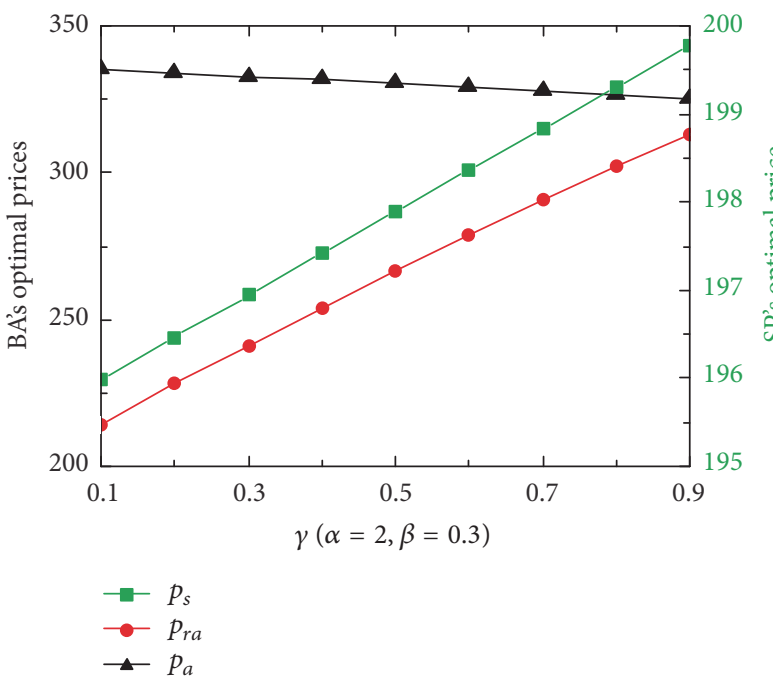

(a)

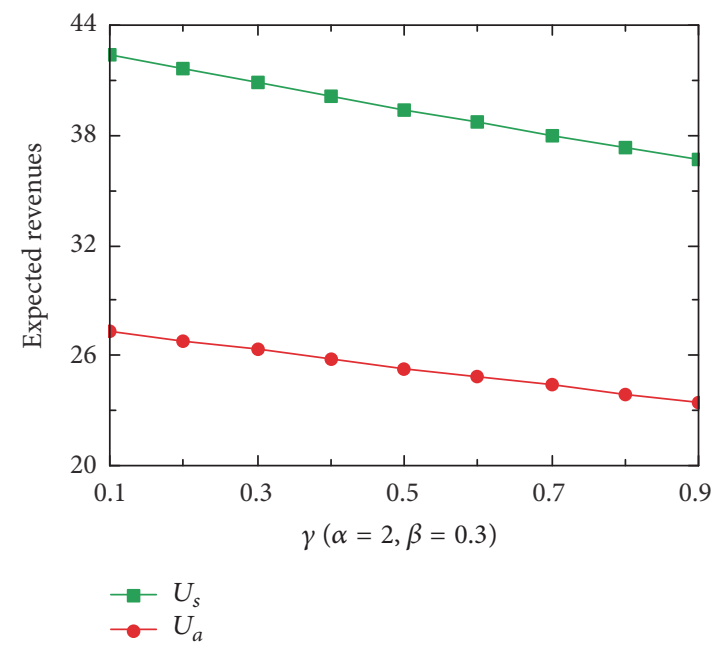

(c)

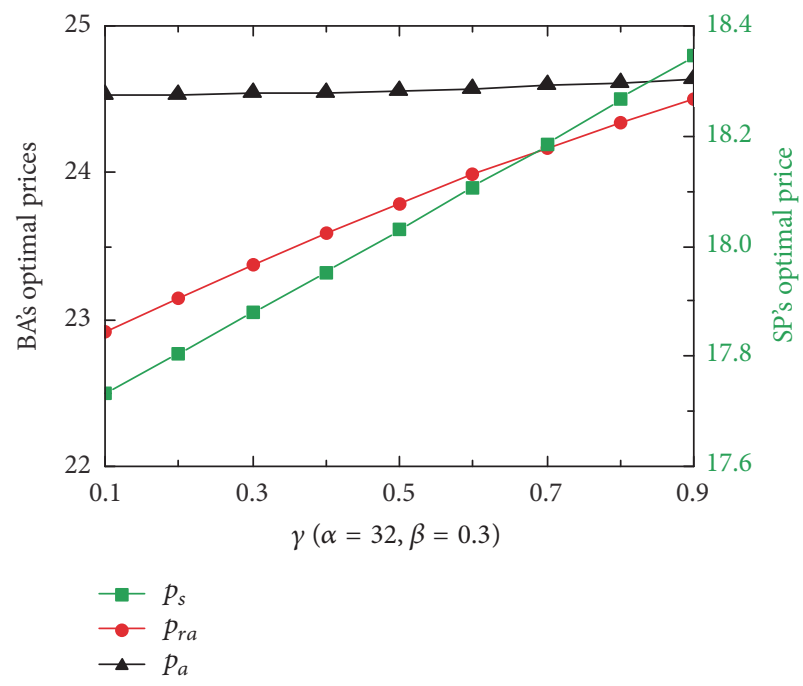

(b)

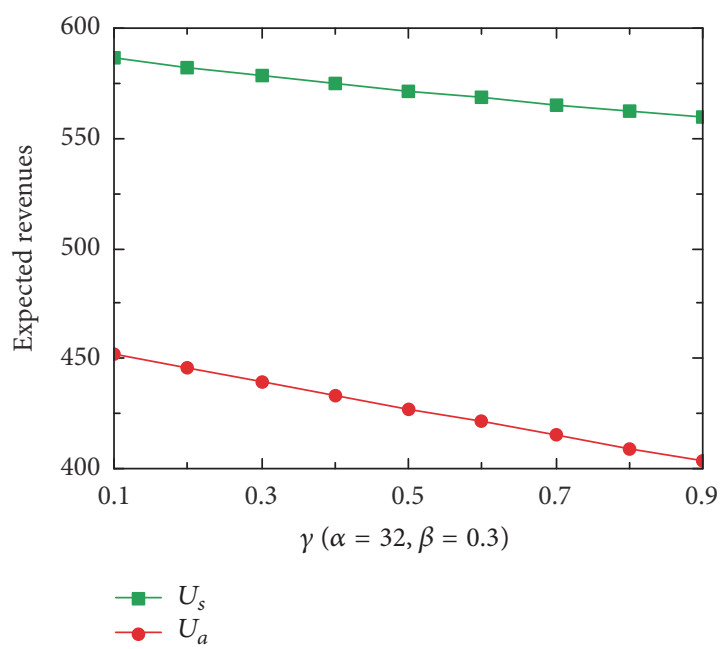

(d)

FIGURE 4: Combined effects of price-sensitivity and bargainers' power on SP's and BA's equilibrium prices and expected revenues. (a) $\alpha=2$ and $\beta=0.3$, (b) $\alpha=32$ and $\beta=0.3$, (c) $\alpha=2$ and $\beta=0.3$, and (d) $\alpha=32$ and $\beta=0.3$.

of a constant elasticity demand with a small price-elasticity index.

The following remark characterizes the combined effects of demand functions and bargainers' power on the SP's and the BA's equilibrium prices and expected revenues.

Remark 6. When the bargainers' bargaining power rises,

(1) the BA's reservation price increases no matter under what kind of demand;

(2) the BA's posted price rises in two situations: under a linear demand with a large price-sensitivity index and under a constant elasticity demand with a small priceelasticity index, but it drops in other situations;

(3) the wholesale price rises except under a constant elasticity demand with a relative large price-elasticity index;
(4) the BA's expected revenue always falls, and the SP's expected revenue shows the same tendency except under a constant elasticity demand with a relative small price-elasticity index.

\section{Conclusion}

Demand forms, SD population structure, and negotiation significantly affect SPs' and BAs' pricing strategies and expected revenues in the CMfg system. In this study, we proposed two two-stage models to analyze the dynamic pricing problem in MSC consisting of SP, BA, and dynamic SD population under linear demand and constant elasticity demand, respectively. In our study, the price competition between the SP and the BA was modeled with a leader-follower game. We considered price takers and bargainers in the models and formulated the negotiation between the BA and bargainers with GNBS. Through solving the two models numerically with PSO based 


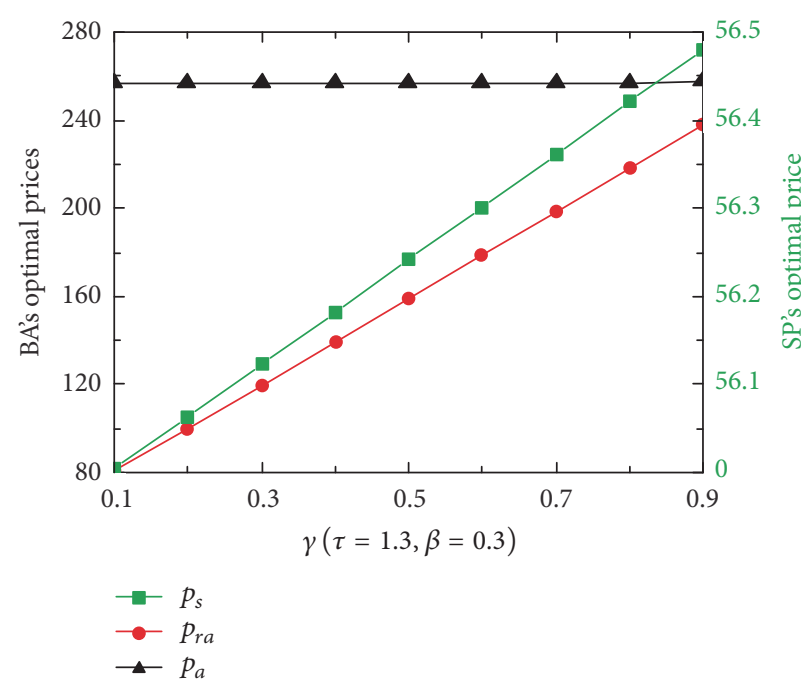

(a)

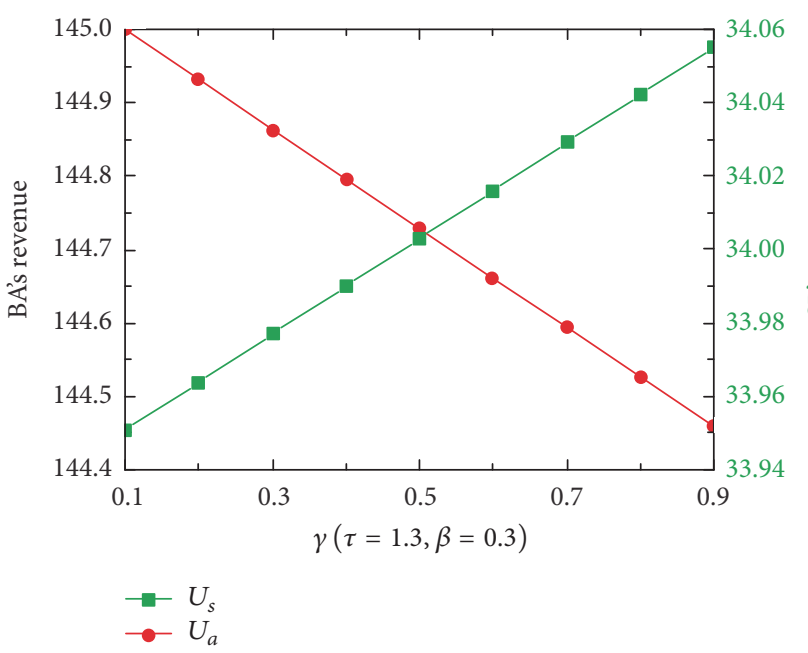

(c)

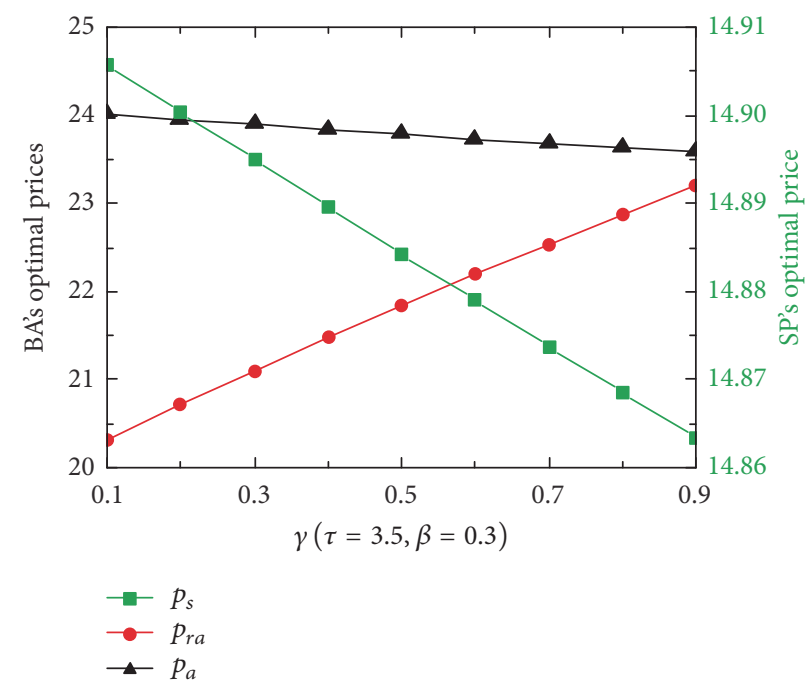

(b)

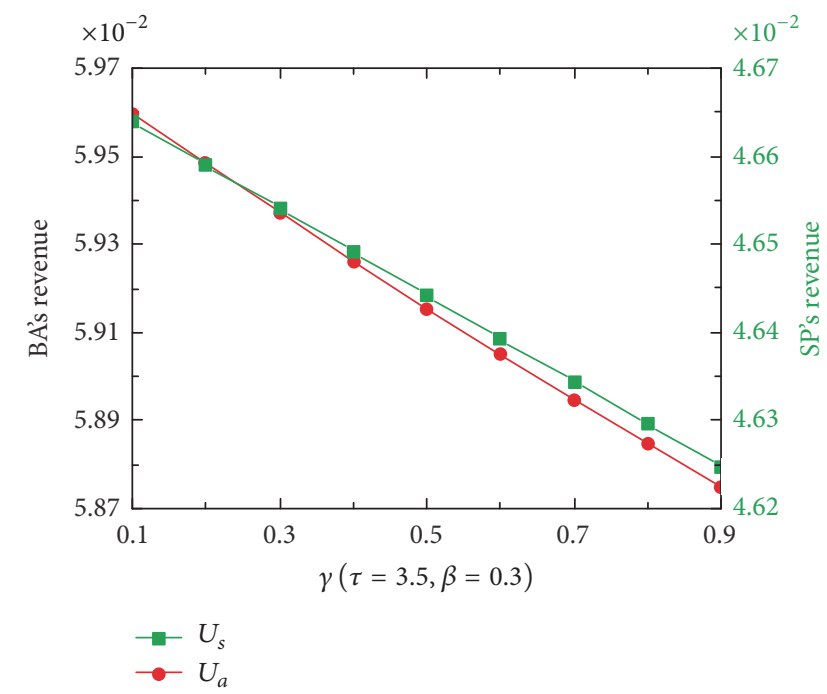

(d)

FIGURE 5: Combined effects of price-elasticity index and bargainers' power on SP's and BA's equilibrium prices and expected revenues. (a) $\tau=1.3$ and $\beta=0.3$, (b) $\tau=3.5$ and $\beta=0.3$, (c) $\tau=1.3$ and $\beta=0.3$, and (d) $\tau=3.5$ and $\beta=0.3$.

algorithm, we developed several insights into the combined influences of demand forms, SD population structure, and negotiation on the SP's and the BA's equilibrium prices and expected revenues. There are three key findings from this study:

(1) The wholesale price, the BA's reservation price, and posted price all decrease nonlinearly with pricesensitivity and price-elasticity index.

(2) The effects of SD population structure and negotiation on equilibrium prices are related to population stability and demand models. With fixed consumer population and linear demand, the optimal posted price and reservation price increase with the proportion of bargainers [24, 25]. But this conclusion is partly valid when the SD population is dynamic.
We found that the optimal wholesale price, the BA's optimal reservation price, and posted price all increase with the proportion of price takers under linear demand but decrease with it under constant elasticity demand. When bargainers' power rises, the $B$ A's reservation price increases no matter what kind of demand is involved, which is in line with Kuo et al's finding [25]. But the BA's posted price only rises with bargainers' power in two situations: under a linear demand with a large price-sensitivity index and under a constant elasticity demand with a small price-elasticity index. The wholesale price rises with bargainers' power except under a constant elasticity demand with a relative large price-elasticity index.

(3) A dynamic SD population with a high ratio of price takers would benefit the SP and the BA as their 
expected revenues go up with the increasing proportion of price takers no matter under what kind of demand. This finding is contrary to the conclusion reached by Kuo et al. [26] who conducted a study in a supply chain with fixed consumer population. The rise of bargainers' power will diminish the BA's expected revenue. However, the SP can benefit from raising the wholesale price with increasing bargainers' power under a constant elasticity demand with a relative small price-elasticity index.

We then state the potential application of our conclusions to the general problem of pricing strategies in a CMfg system. Firstly, we find that whether the wholesale price should rise with increasing proportion of price takers depends on the demand form. Although a high wholesale price might increase the surplus, raising the wholesale price with the proportion of price takers is not an optimal measure for SPs when facing a constant elasticity demand. Secondly, BA should follow the monopoly SP's strategy when consumer structure changes as the optimal prices have the same trend in this situation. Thirdly, since the BA's optimal reservation price rises with the bargainers' power regardless of demand forms, it is appropriate for BA to set a high reservation price when facing powerful bargainers. Fourthly, although they do not interact with bargainers directly, SPs should adjust the wholesale price according to bargainers' power, especially under a constant elasticity demand. When price-elasticity index is small, increasing the wholesale price with increasing power of bargainers would benefit them.

This study also has several limitations. First of all, a momentous assumption made in this study is that the price takers' demand and the bargainers' initial demand follow the same law. However, some bargainers may decide their initial demand casually as they can modify their needs in a negotiation. Therefore, a possible direction of future research would be to investigate whether the uncertainty of bargainers' demand has significant impact on pricing process. Another limitation is that we considered that the bargainers' valuations follow a uniform distribution. But such an assumption cannot cover all the cases. In some situations, other distributions (e.g., Gaussian distribution) might be more suitable. Our further study would explore the effect of the distribution of bargainers' valuations on equilibrium prices in the CMfg system.

Despite these limitations, this research extends our knowledge of dynamic pricing in the CMfg system through investigating the combined effects of consumer structure, negotiation, and demand forms on pricing strategies. Our study complements previous studies and provides support for further research in this area.

\section{Appendix}

Proof of Proposition 2. We first prove that, for a given $p_{a}$, $U_{a}\left(p_{a}, p_{r a}\right)$ (as shown in (8)) is unimodal with respect to $p_{r a}$ for $p_{r a} \in\left[p_{s}+c_{a}, p_{a}\right]$. This can be guaranteed by the following claims: (i) $U_{a}\left(p_{a}, p_{r a}\right)$ is concave in $p_{r a}$, (ii) $\left.\left(\partial U_{a}\left(p_{a}, p_{r a}\right) / \partial p_{r a}\right)\right|_{p_{r a}=p_{s}+c_{a}} \geq 0$, and (iii) $\left(\partial U_{a}\left(p_{a}, p_{r a}\right) /\right.$ $\left.\partial p_{r a}\right)\left.\right|_{p_{r a}=p_{a}} \leq 0$.

The first and second derivatives of $U_{a}\left(p_{a}, p_{r a}\right)$ (as shown in (8)) with respect to $p_{r a}$ are

$$
\begin{aligned}
& \frac{\partial U_{a}\left(p_{a}, p_{r a}\right)}{\partial p_{r a}} \\
& =\frac{(1-\beta)\left(d_{0}-\alpha p_{a}\right)\left[(1-\gamma)\left(c_{a}+p_{s}\right)+\gamma p_{a}-p_{r a}\right]}{h(1-\gamma)}, \\
& \frac{\partial U_{a}\left(p_{a}, p_{r a}\right)}{\partial p_{r a}^{2}}=-\frac{(1-\beta)\left(d_{0}-\alpha p_{a}\right)}{h(1-\gamma)} .
\end{aligned}
$$

Since $d_{0}-\alpha p_{a} \geq 0$, claim (i) follows directly from (A.2). And as

$$
\begin{aligned}
& \left.\frac{\partial U_{a}\left(p_{a}, p_{r a}\right)}{\partial p_{r a}}\right|_{p_{r a}=p_{s}+c_{a}} \\
& =\frac{\gamma(1-\beta)\left(d_{0}-\alpha p_{a}\right)\left(p_{a}-p_{s}-c_{a}\right)}{h(1-\gamma)} \geq 0, \\
& \left.\frac{\partial U_{a}\left(p_{a}, p_{r a}\right)}{\partial p_{r a}}\right|_{p_{r a}=p_{a}} \\
& =-\frac{(1-\beta)\left(d_{0}-\alpha p_{a}\right)\left(p_{a}-p_{s}-c_{a}\right)}{h} \leq 0,
\end{aligned}
$$

we thus complete the proof of claims (ii) and (iii).

We then turn to prove that there exists a unique posted price, $p_{a} \in\left[p_{r a}, h\right]$, which maximizes $U_{a}\left(p_{a}, p_{r a}\right)$ when $p_{r a}$ takes its optimal value. Let (A.1) equal zero; we get the optimal value of $p_{r a}$ as follows:

$$
p_{r a}^{*}=\gamma p_{a}+(1-\gamma)\left(p_{s}+c_{a}\right) .
$$

Then the first and second derivatives of $U_{a}\left(p_{a}, p_{r a}^{*}\right)$ with respect to $p_{a}$ are

$$
\begin{aligned}
& \frac{\partial U_{a}\left(p_{a}, p_{r a}^{*}\right)}{\partial p_{a}}=\frac{1}{2 h}\left\{\alpha(-1+\beta+\gamma-\beta \gamma) c_{a}^{2}\right. \\
& +2 d_{0}\left(h-(1-\beta) c_{b}\right. \\
& \left.-(1-\beta)\left((1+\gamma) p_{a}-\gamma p_{s}\right)\right)+2(1-\beta) c_{a}\left(-\alpha c_{b}\right. \\
& \left.+\gamma d_{0}+\alpha\left(h-2 \gamma p_{a}-(1-\gamma) p_{s}\right)\right) \\
& +\alpha\left(3(1-\beta)(1+\gamma) p_{a}^{2}\right. \\
& +p_{s}\left(2 h-2(1-\beta) c_{b}-(1-\beta)(1-\gamma) p_{s}\right) \\
& \left.\left.-4 p_{a}\left(h-(1-\beta) c_{b}+(1-\beta) \gamma p_{s}\right)\right)\right\}, \\
& \frac{\partial U_{a}}{\left(p_{a}, p_{r a}^{*}\right)} \\
& \quad \partial p_{a}^{2} \\
& -\beta) c_{b}-d_{0}+3 \alpha p_{a}+(\beta-(1-\beta) \gamma)\left(d_{0}-3 \alpha p_{a}\right) \\
& \left.-2 \alpha(1-\beta) \gamma p_{s}\right\} .
\end{aligned}
$$


Let (A.6) equal zero; then we have

$$
\frac{\partial U_{a}\left(p_{a}, p_{r a}^{*}\right)}{\partial p_{a}^{2}} \begin{cases}\leq 0 & \text { if } p_{a} \leq \theta_{a} \\ \geq 0 & \text { if } p_{a} \geq \theta_{a}\end{cases}
$$

where $\theta_{a}=\left(2 h \alpha+2 \alpha(1-\beta) \gamma c_{a}-2 \alpha(1-\beta) c_{b}+(1-\beta)((1+\right.$ $\left.\left.\gamma) d_{0}+2 \alpha \gamma p_{s}\right)\right) /(3 \alpha(1-\beta)(1+\gamma))$.

Equation (A.7) indicates that $U_{a}\left(p_{a}, p_{r a}^{*}\right)$ is concave when $p_{a} \leq \theta_{a}$ and convex when $p_{a} \geq \theta_{a}$. Thus, we only need to prove that the optimal value of $p_{a}$ is located in $\left[p_{r a}^{*}, \theta_{a}\right]$. As $p_{r a}^{*} \geq p_{s}+c_{a}$, the interval should be changed to $\left[p_{s}+c_{a}, \theta_{a}\right]$. Next we prove the following claim: (iv) $\left.\left(\partial U_{a}\left(p_{a}, p_{r a}^{*}\right) / \partial p_{a}\right)\right|_{p_{a}=p_{s}+c_{a}} \geq 0$.

Substituting $p_{a}=p_{s}+c_{a}$ into (A.5) yields

$$
\begin{aligned}
& \left.\frac{\partial U_{a}\left(p_{a}, p_{r a}^{*}\right)}{\partial p_{a}}\right|_{p_{a}=p_{s}+c_{a}}=\frac{1}{h}\left\{\alpha(1-\beta) c_{a}^{2}\right. \\
& -c_{a}\left(h \alpha(1+\beta)-\alpha(1-\beta) c_{b}+(1-\beta) d_{0}\right. \\
& \left.-2 \alpha(1-\beta) p_{s}\right)+\left(h-(1-\beta) c_{b}-(1-\beta) p_{s}\right) \\
& \left.\cdot\left(d_{0}-\alpha p_{s}\right)\right\} .
\end{aligned}
$$

From the constraints of (8), we know that $h-p_{s}-c_{b}-c_{a} \geq 0$. Let $A$ denote the left-hand side term of (A.8); then we have

$$
\begin{aligned}
A & =\frac{1}{h}\left\{\left(d_{0}-\alpha p_{s}\right)\left[h-(1-\beta)\left(c_{b}+p_{s}\right)\right]\right. \\
& -c_{a}\left[h \alpha(1+\beta)-\alpha(1-\beta)\left(p_{s}+c_{b}+c_{a}\right)\right. \\
& \left.\left.+(1-\beta)\left(d_{0}-\alpha p_{s}\right)\right]\right\}=\frac{1}{h}\left\{\left(d_{0}-\alpha p_{s}\right)[h\right. \\
& \left.-(1-\beta)\left(p_{s}+c_{b}+c_{a}\right)\right]-\alpha c_{a}[h(1+\beta) \\
& \left.\left.-(1-\beta)\left(p_{s}+c_{b}+c_{a}\right)\right]\right\}=\frac{1}{h}\left\{\left(d_{0}-\alpha p_{s}\right)[h\right. \\
& \left.-(1-\beta)\left(p_{s}+c_{b}+c_{a}\right)\right]-\alpha c_{a}[h \\
& \left.\left.-(1-\beta)\left(p_{s}+c_{b}+c_{a}\right)\right]-\alpha \beta h c_{a}\right\}=\frac{1}{h}\{[h \\
& \left.-(1-\beta)\left(p_{s}+c_{b}+c_{a}\right)\right]\left(d_{0}-\alpha p_{s}-\alpha c_{a}\right) \\
& \left.-\alpha \beta h c_{a}\right\} \geq \frac{1}{h}\left\{\left[(1-\beta)\left(h-p_{s}-c_{b}-c_{a}\right)+\beta h\right]\right. \\
& \left.+\left(\alpha h-\alpha p_{s}-\alpha c_{a}\right)-\alpha \beta h c_{a}\right\} \geq \frac{1}{h}\left\{\alpha \beta h c_{b}\right. \\
& \left.-\alpha \beta h c_{a}\right\} \geq 0 .
\end{aligned}
$$

Therefore, claim (iv) holds.

To finish the proof, next we prove that the optimal value of $p_{a}$ is less than $\theta_{a}$. Assume that there exist $\mu_{1}\left(\mu_{1}>1\right)$ that makes $\mu_{1}\left(p_{s}+c_{a}\right)$ be a zero solution of (A.5) and $\mu_{2}\left(\mu_{2}>1\right)$ that makes $\mu_{2}\left(p_{s}+c_{a}\right)=\theta_{a}$. If we prove that $\mu_{1} \leq \mu_{2}$, then Proposition 2 is true.
Let (A.5) equal zero; then we obtain two solutions of $\mu_{1}$ as follows:

$$
\begin{aligned}
& \mu_{11}=\frac{B-C}{D} \\
& \mu_{12}=\frac{B+C}{D},
\end{aligned}
$$

where

$$
\begin{aligned}
B= & 2 h \alpha+2 \alpha(1-\beta) \gamma c_{a}-2 \alpha(1-\beta) c_{b}+(1-\beta) \\
& \cdot\left[(1+\gamma) d_{0}+2 \alpha \gamma p_{s}\right], \\
C & =\left\{\left[-2 h \alpha-2 \alpha(1-\beta) \gamma c_{a}+2 \alpha(1-\beta) c_{b}\right.\right. \\
& \left.-(1-\beta)\left((1+\gamma) d_{0}+2 \alpha \gamma p_{s}\right)\right]^{2}+3 \alpha(1-\beta)(1 \\
& +\gamma)\left[\alpha(1-\beta)(1-\gamma) c_{a}^{2}\right. \\
& -2(1-\beta)\left(h \alpha-\alpha c_{b}+\gamma d_{0}-\alpha(1-\gamma) p_{s}\right) c_{a} \\
& -\alpha p_{s}\left(2 h-2(1-\beta) c_{b}-(1-\beta)(1-\gamma) p_{s}\right) \\
& \left.\left.-2 d_{0}\left(h-(1-\beta) c_{b}+(1-\beta) \gamma p_{s}\right)\right]\right\}^{1 / 2}, \\
D & =3 \alpha(1-\beta)(1+\gamma)\left(c_{a}+p_{s}\right) .
\end{aligned}
$$

Obviously, $B, C$, and $D$ are all positive. Since claim (iv) has been proven to be true, the zero solutions of (A.5) are sure to be larger than $p_{s}+c_{a}$. Therefore, $\mu_{11}$ and $\mu_{12}$ are all greater than one. According to (A.7), only the smaller one of the two zero solutions of (A.5) can maximize $U_{a}\left(p_{a}, p_{r a}^{*}\right)$. Thus, let $\mu_{1}=$ $\mu_{11}$. We can also get the value of $\mu_{2}$ as follows:

$$
\mu_{2}=\frac{B}{D} \text {. }
$$

Subtracting $\mu_{1}$ from $\mu_{2}$ yields

$$
\mu_{2}-\mu_{1}=\frac{C}{D} \geq 0 .
$$

Thus we complete the proof.

Proof of Proposition 3. We first prove that, for given $p_{a}$, $U_{a}\left(p_{a}, p_{r a}\right)$ (as shown in (10)) is unimodal with respect to $p_{r a}$ for $p_{r a} \in\left[p_{s}+c_{a}, p_{a}\right]$. This can be guaranteed by the following claims: (i) $U_{a}\left(p_{a}, p_{r a}\right)$ is concave in $p_{r a}$, (ii) $\left.\left(\partial U_{a}\left(p_{a}, p_{r a}\right) / \partial p_{r a}\right)\right|_{p_{r a}=p_{s}+c_{a}} \geq 0$, and (iii) $\left(\partial U_{a}\left(p_{a}, p_{r a}\right) /\right.$ $\left.\partial p_{r a}\right)\left.\right|_{p_{r a}=p_{a}} \leq 0$.

The first and second derivatives of $U_{a}\left(p_{a}, p_{r a}\right)$ (as shown in (10)) with respect to $p_{r a}$ are

$$
\begin{aligned}
& \frac{\partial U_{a}\left(p_{a}, p_{r a}\right)}{\partial p_{r a}} \\
& =\frac{d_{0} p_{a}^{-\tau}(1-\beta)\left((1-\gamma)\left(p_{s}+c_{a}\right)+\gamma p_{a}-p_{r a}\right)}{h(1-\gamma)}, \\
& \frac{\partial U_{a}\left(p_{a}, p_{r a}\right)}{\partial p_{r a}^{2}}=-\frac{(1-\beta) d_{0} p_{a}^{-\tau}}{h(1-\gamma)} .
\end{aligned}
$$


Since $d_{0} p_{a}^{-\tau} \geq 0$, claim (i) follows directly from (A.15). As

$$
\begin{aligned}
& \left.\frac{\partial U_{a}\left(p_{a}, p_{r a}\right)}{\partial p_{r a}}\right|_{p_{r a}=p_{s}+c_{a}} \\
& =\frac{\gamma(1-\beta) d_{0} p_{a}^{-\tau}\left(p_{a}-p_{s}-c_{a}\right)}{h(1-\gamma)} \geq 0, \\
& \left.\frac{\partial U_{a}\left(p_{a}, p_{r a}\right)}{\partial p_{r a}}\right|_{p_{r a}=p_{a}} \\
& =-\frac{(1-\beta) d_{0} p_{a}^{-\tau}\left(p_{a}-p_{s}-c_{a}\right)}{h} \leq 0,
\end{aligned}
$$

we thus finish the proof of claims (ii) and (iii).

Next we prove that there exists a unique posted price, $p_{a} \in\left[p_{r a}, h\right]$, which maximizes $U_{a}\left(p_{a}, p_{r a}\right)$ when $p_{r a}$ takes its optimal value. The optimal value of $p_{r a}$ is the same one shown in (A.4).

To begin with, we give the proof for the following claims: (iv) $\left.\left(\partial U_{a}\left(p_{a}, p_{r a}^{*}\right) / \partial p_{a}\right)\right|_{p_{a}=p_{s}+c_{a}} \geq 0$ and (v) $\left.\left(\partial U_{a}\left(p_{a}, p_{r a}^{*}\right) / \partial p_{a}\right)\right|_{p_{a}=h} \leq 0$.

The first derivative of $U_{a}\left(p_{a}, p_{r a}^{*}\right)$ is

$$
\begin{aligned}
& \frac{\partial U_{a}\left(p_{a}, p_{r a}^{*}\right)}{\partial p_{a}}=-\frac{1}{2 h} d_{0} p_{a}^{-1-\tau}\left\{\tau(1-\beta)(1-\gamma) c_{a}^{2}\right. \\
& +(2-\tau)(1-\beta)(1+\gamma) p_{a}^{2}-2(1-\beta) \\
& \cdot\left[h \tau-\tau c_{b}+(1-\tau) \gamma p_{a}-\tau(1-\gamma) p_{s}\right] c_{a} \\
& -\tau\left[2 h-2(1-\beta) c_{b}-(1-\beta)(1-\gamma) p_{s}\right] p_{s} \\
& \left.-2(1-\tau)\left[h-(1-\beta) c_{b}+(1-\beta) \gamma p_{s}\right] p_{a}\right\} .
\end{aligned}
$$

Substituting $p_{a}=p_{s}+c_{a}$ into (A.17) yields

$$
\begin{aligned}
& \left.\frac{\partial U_{a}\left(p_{a}, p_{r a}^{*}\right)}{\partial p_{a}}\right|_{p_{a}=p_{s}+c_{a}}=\frac{1}{h} d_{0}\left(p_{s}+c_{a}\right)^{-1-\tau} \\
& \cdot\left\{-(1-\beta) c_{a}^{2}+\left[h-(1-\beta) c_{b}-(1-\beta) p_{s}\right] p_{s}\right. \\
& \left.+\left[(1-\tau \beta) h-(1-\beta) c_{b}-2(1-\beta) p_{s}\right] c_{a}\right\} .
\end{aligned}
$$

Let $\left.\left(\partial U_{a}\left(p_{a}, p_{r a}^{*}\right) / \partial p_{a}\right)\right|_{p_{a}=p_{s}+c_{a}} \geq 0$; then we have

$$
\tau \leq \frac{\left(p_{s}+c_{a}\right)\left[h-(1-\beta)\left(p_{s}+c_{a}+c_{b}\right)\right]}{\beta h c_{a}} .
$$

Therefore, claim (iv) holds when condition (A.19) is satisfied. Substituting $p_{a}=h$ into (A.17) yields

$$
\begin{gathered}
\left.\frac{\partial U_{a}\left(p_{a}, p_{r a}^{*}\right)}{\partial p_{a}}\right|_{p_{a}=h}=-\frac{1}{2} d_{0} h^{-2-\tau}\{(2-\tau)(1-\beta) \\
\cdot(1+\gamma) h^{2}+\tau(1-\beta)(1-\gamma) c_{a}^{2}-2(1-\beta)
\end{gathered}
$$

$$
\begin{aligned}
& \cdot\left[(\tau+\gamma-\tau \gamma) h-\tau c_{b}-\tau(1-\gamma) p_{s}\right] c_{a} \\
& -\tau\left[2 h-2(1-\beta) c_{b}-(1-\beta)(1-\gamma) p_{s}\right] p_{s} \\
& \left.-2 h(1-\tau)\left[h-(1-\beta) c_{b}+(1-\beta) \gamma p_{s}\right]\right\} .
\end{aligned}
$$

Let $\left.\left(\partial U_{a}\left(p_{a}, p_{r a}^{*}\right) / \partial p_{a}\right)\right|_{p_{a}=h} \leq 0$; then we have

$$
\tau \geq \max \left(1, \frac{2 h E_{1}}{E_{2}+E_{3}}\right),
$$

where $E_{1}=(\beta-\gamma+\beta \gamma) h+(1-\beta) \gamma c_{a}-(1-\beta) c_{b}+(1-\beta) \gamma p_{s}$, $E_{2}=(1-\beta)(1-\gamma) c_{a}^{2}+2(1-\beta)\left[c_{b}-(1-\gamma)\left(h-p_{s}\right)\right] c_{a}$, and $E_{3}=\left(h-p_{s}\right)\left[(1+\beta-\gamma+\beta \gamma) h-2(1-\beta) c_{b}-(1-\beta)(1-\gamma) p_{s}\right]$. Thus, claim (v) holds when condition (A.21) is satisfied.

We then prove that $U_{a}\left(p_{a}, p_{r a}^{*}\right)$ has only one maximum value in the predefined interval. To do this, we attest that (A.17) has only one zero solution in $\left[p_{s}+c_{a}, h\right]$. Let

$$
\begin{aligned}
& G\left(p_{a}\right)=\tau(1-\beta)(1-\gamma) c_{a}^{2}+(2-\tau)(1-\beta) \\
& \cdot(1+\gamma) p_{a}^{2}-2(1-\beta) \\
& \cdot\left[h \tau-\tau c_{b}+(1-\tau) \gamma p_{a}-\tau(1-\gamma) p_{s}\right] c_{a} \\
& \quad-\tau\left[2 h-2(1-\beta) c_{b}-(1-\beta)(1-\gamma) p_{s}\right] p_{s} \\
& \quad-2(1-\tau)\left[h-(1-\beta) c_{b}+(1-\beta) \gamma p_{s}\right] p_{a} .
\end{aligned}
$$

Obviously, $G\left(p_{a}\right)$ is continuous with respect to $p_{a}$. If conditions (A.19) and (A.21) are satisfied, then $G\left(p_{s}+c_{a}\right) \leq 0$ and $G(h) \geq 0$, which implies that there exists at least one zero solution in the predefined interval. The following analysis is conducted under the assumption that the two conditions are all satisfied. Note that the behavior of $G\left(p_{a}\right)$ depends on $\tau$; thus we consider three situations: $\tau=2,1<\tau<2$, and $\tau>2$.

(1) $\tau=2$. $G\left(p_{a}\right)$ is a linear function. Consequently, it has only one zero solution in $\left[p_{s}+c_{a}, h\right]$.

(2) $1<\tau<2 . G\left(p_{a}\right)$ is a parabola and opens upward. It has two zero solutions. Since $G\left(p_{s}+c_{a}\right) \leq 0$ and $G(h) \geq 0$, there is only one zero solution in $\left[p_{s}+c_{a}, h\right]$.

(3) $\tau>2 . G\left(p_{a}\right)$ is a parabola and opens downward. Assume that there are two zero solutions in the predefined interval. Then we have $G(h) \leq 0$, which is in conflict with the known condition. Therefore, $G\left(p_{a}\right)$ has only one zero solution in $\left[p_{s}+\right.$ $\left.c_{a}, h\right]$. Thus we complete the proof.

\section{Abbreviations}

$p_{a}$ : Posted price set by the BA

$p_{s}$ : Wholesale price set by the SP

$p_{b}$ : Final price accepted by both the BA and bargainers

$U_{a}$ : Expected revenue of the BA

$U_{s}$ : Expected revenue of the SP

$\alpha$ : Price-sensitivity, $\alpha>0$ 
$d$ : SDs' total demand

$d_{0}$ : A positive constant which embodies the effects of all factors other than price on demand

$F(\cdot)$ : Cumulative distribution function of the bargainers' valuations

$\bar{F}(\cdot): 1-F(\cdot)$

$f(\cdot)$ : Probability density function of the bargainers' valuations

$\beta$ : The proportion of the demand from price takers (and the proportion of price takers in the SD population), $0<\beta<1$

$c_{s}$ : Unit service cost of the SP

$p_{v}$ : A bargainer's valuation of the services needed

$p_{r a}:$ Reservation price of the BA

$\gamma$ : Bargainers' bargaining power, $0<\gamma<1$

$c_{b}$ : Unit bargaining cost of the bargainers

$c_{a}$ : Unit bargaining cost of the BA, $c_{a}<c_{b}$

$\tau$ : $\quad$ Price-elasticity index, $\tau>1$

$h$ : Upper bound of the bargainers' valuations.

\section{Competing Interests}

The authors declare that they have no competing interests.

\section{Acknowledgments}

This research was supported by the National ScienceTechnology Support Plan Project (no. 2015BAF32B03).

\section{References}

[1] L. Zhang, Y. Luo, F. Tao et al., "Cloud manufacturing: a new manufacturing paradigm," Enterprise Information Systems, vol. 8, no. 2, pp. 167-187, 2014.

[2] C. S. Yeo, S. Venugopal, X. Chu, and R. Buyya, "Autonomic metered pricing for a utility computing service," Future Generation Computer Systems, vol. 26, no. 8, pp. 1368-1380, 2010.

[3] X. Wang, Development of an interoperable cloud-based manufacturing system [Ph.D. thesis], The University of Auckland, 2012.

[4] D. Wu, M. J. Greer, D. W. Rosen, and D. Schaefer, "Cloud manufacturing: strategic vision and state-of-the-art," Journal of Manufacturing Systems, vol. 32, no. 4, pp. 564-579, 2013.

[5] H. Xu and B. Li, "Maximizing revenue with dynamic cloud pricing: the infinite horizon case," in Proceedings of the IEEE International Conference on Communications (ICC '12), pp. 2929-2933, June 2012.

[6] Q. Zhang, Q. Zhu, and R. Boutaba, "Dynamic resource allocation for spot markets in cloud computing environments," in Proceedings of the 4th IEEE/ACM International Conference on Cloud and Utility Computing (UCC '11), pp. 178-185, Melbourne, Australia, December 2011.

[7] C. Wang, J. Chen, B. B. Zhou, and A. Y. Zomaya, "Just satisfactory resource provisioning for parallel applications in the cloud," in Proceedings of the IEEE 8th World Congress on Services (SERVICES '12), pp. 285-292, Honolulu, Hawaii, USA, June 2012.

[8] C.-C. Hsieh, Y.-T. Liu, and W.-M. Wang, "Coordinating ordering and pricing decisions in a two-stage distribution system with price-sensitive demand through short-term discounting,"
European Journal of Operational Research, vol. 207, no. 1, pp. 142-151, 2010.

[9] Y. Feng, B. Li, and B. Li, "Price competition in an oligopoly market with multiple IaaS cloud providers," IEEE Transactions on Computers, vol. 63, no. 1, pp. 59-73, 2014.

[10] D. Ma and J. Huang, "The pricing model of cloud computing services," in Proceedings of the 14th Annual International Conference on Electronic Commerce (ICEC '12), pp. 263-269, Singapore, Singapore, August 2012.

[11] K. Sowmya and R. P. Sundarraj, "Strategic bidding for cloud resources under dynamic pricing schemes," in Proceedings of the International Symposium on Cloud and Services Computing (ISCOS '12), pp. 25-30, IEEE, Mangalore, India, December 2012.

[12] T. Truong-Huu and C.-K. Tham, "A game-theoretic model for dynamic pricing and competition among cloud providers," in Proceedings of the IEEE/ACM 6th International Conference on Utility and Cloud Computing (UCC '13), pp. 235-238, Dresden, Germany, December 2013.

[13] M. Mihailescu and Y. M. Teo, "Strategy-proof dynamic resource pricing of multiple resource types on federated clouds," in Proceedings of the International Conference on Algorithms and Architectures for Parallel Processing, pp. 337-350, Busan, Republic of Korea, May 2010.

[14] D. Niu, C. Feng, and B. Li, "Pricing cloud bandwidth reservations under demand uncertainty," in Proceedings of the 12th Joint International Conference on Measurement and Modeling of Computer Systems, ACM (SIGMETRICS '12), pp. 151-162, ACM, London, UK, June 2012.

[15] H. Xu and B. Li, "Dynamic cloud pricing for revenue maximization," IEEE Transactions on Cloud Computing, vol. 1, no. 2, pp. 158-171, 2013.

[16] M. Macías and J. Guitart, "A genetic model for pricing in cloud computing markets," in Proceedings of the 26th Annual ACM Symposium on Applied Computing (SAC '11), pp. 113-118, Taichung, Taiwan, 2011.

[17] S. Qanbari, F. Li, S. Dustdar et al., "An economic model for utilizing cloud computing resources via pricing elasticity of demand and supply," in Proceedings of the International Conference on Cloud Computing and Services Science, pp. 47-62, Lisbon, Portugal, May 2015.

[18] M. Al-Roomi, S. Al-Ebrahim, S. Buqrais, and I. Ahmad, "Cloud computing pricing models: a survey," International Journal of Grid and Distributed Computing, vol. 6, no. 5, pp. 93-106, 2013.

[19] S. C. M. Lee and J. C. S. Lui, "On the interaction and competition among Internet service providers," IEEE Journal on Selected Areas in Communications, vol. 26, no. 7, pp. 1277-1283, 2008.

[20] J. Anselmi, D. Ardagna, J. C. Lui, A. Wierman, Y. Xu, and Z. Yang, "The economics of the cloud: price competition and congestion," ACM SIGecom Exchanges, vol. 13, no. 1, pp. 58-63, 2014.

[21] A. V. Dastjerdi and R. Buyya, "An autonomous reliability-aware negotiation strategy for cloud computing environments," in Proceedings of the 12th IEEE/ACM International Symposium on Cluster, Cloud and Grid Computing (CCGrid '12), pp. 284-291, Ottawa, Canada, May 2012.

[22] K. M. Sim, "Complex and concurrent negotiations for multiple interrelated e-markets," IEEE Transactions on Cybernetics, vol. 43, no. 1, pp. 230-245, 2013.

[23] D. Gill and J. Thanassoulis, "The impact of bargaining on markets with price takers: too many bargainers spoil the broth," European Economic Review, vol. 53, no. 6, pp. 658-674, 2009. 
[24] D. Gill and J. Thanassoulis, "Competition in posted prices with bargaining," Discussion Paper 639, University of Oxford, Department of Economics, Oxford, UK, 2013.

[25] C.-W. Kuo, R.-S. Guo, and Y.-F. Wu, “Optimal pricing strategies under co-existence of price-takers and bargainers in a supply chain," Journal of the Operational Research Society, vol. 63, no. 7, pp. 865-882, 2012.

[26] C.-W. Kuo, H.-S. Ahn, and G. Aydın, "Dynamic pricing of limited inventories when customers negotiate," Operations Research, vol. 59, no. 4, pp. 882-897, 2011.

[27] Z. Kong, B. Tuffin, Y.-K. Kwok, and J. Wang, "Analysis of duopoly price competition between WLAN providers," in Proceedings of the IEEE International Conference on Communications (ICC '09), pp. 1-5, Dresden, Germany, June 2009.

[28] S.-H. Chun and B.-S. Choi, "Service models and pricing schemes for cloud computing," Cluster Computing, vol. 17, no. 2, pp. 529-535, 2014.

[29] A. Muthoo, Bargaining Theory with Applications, Cambridge University Press, Cambridge, UK, 1999.

[30] Y. Gao, G. Zhang, J. Lu, and H.-M. Wee, "Particle swarm optimization for bi-level pricing problems in supply chains," Journal of Global Optimization, vol. 51, no. 2, pp. 245-254, 2011.

[31] A. Rezaee Jordehi and J. Jasni, "Parameter selection in particle swarm optimisation: a survey," Journal of Experimental and Theoretical Artificial Intelligence, vol. 25, no. 4, pp. 527-542, 2013. 


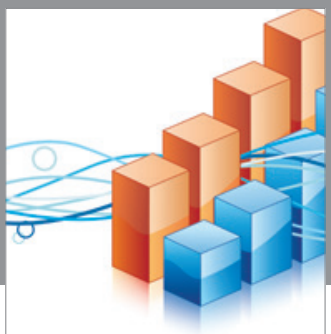

Advances in

Operations Research

vatem alat4

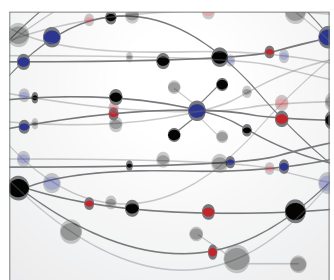

\section{The Scientific} World Journal
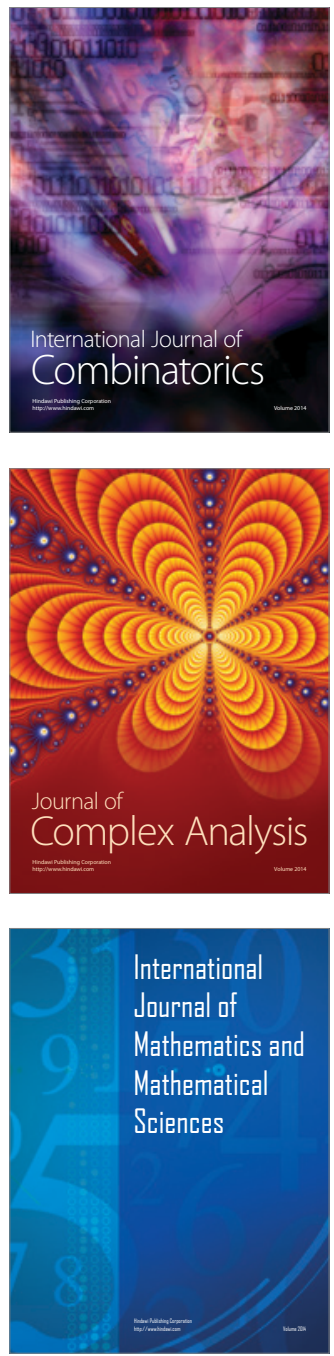
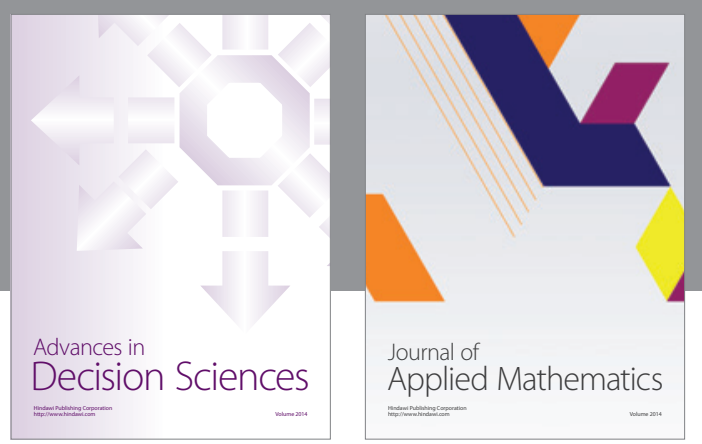

Algebra

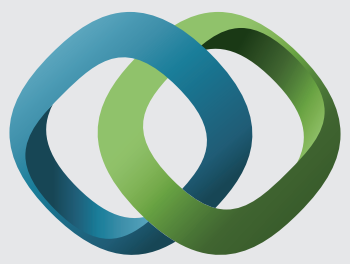

\section{Hindawi}

Submit your manuscripts at

https://www.hindawi.com
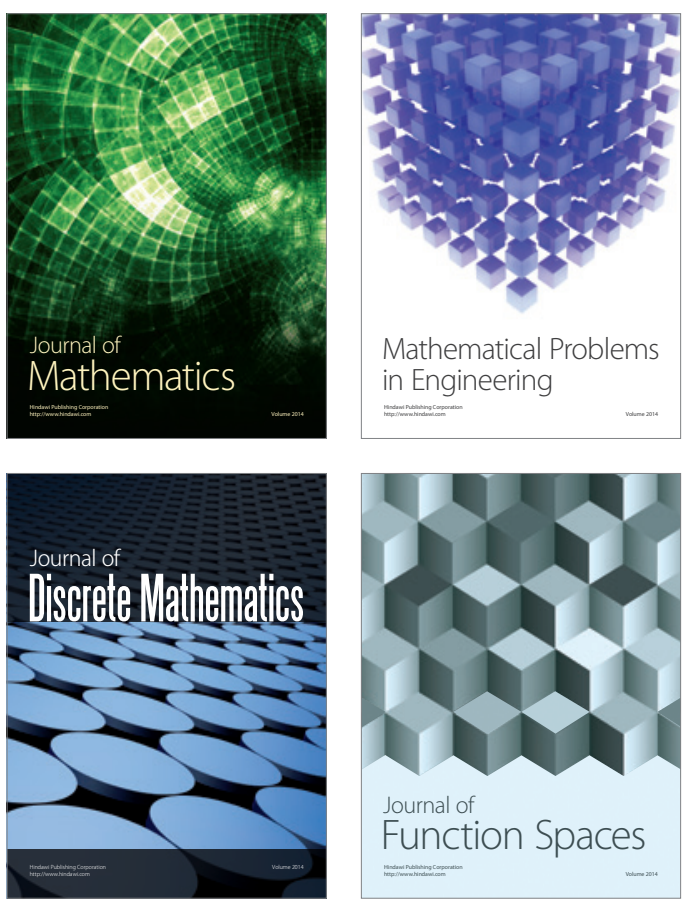

Mathematical Problems in Engineering
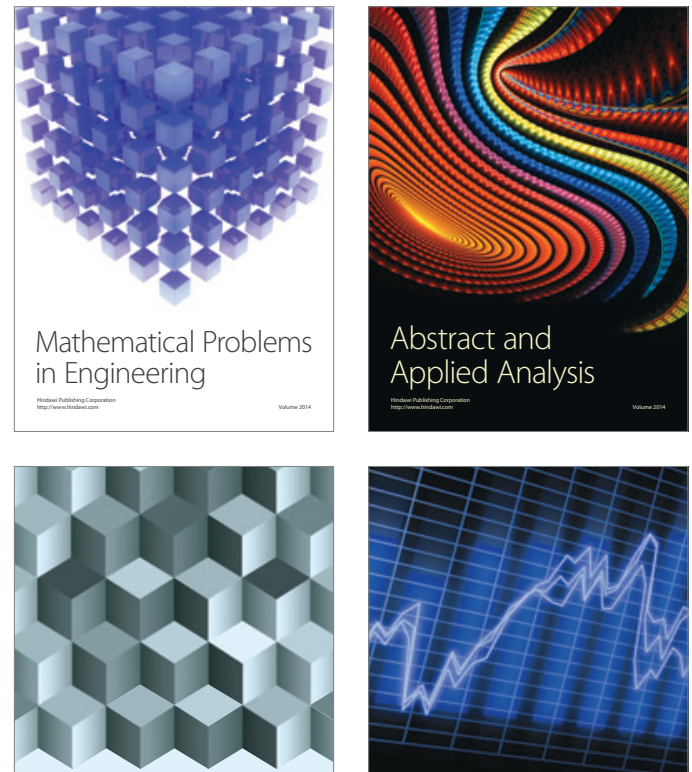

Journal of

Function Spaces

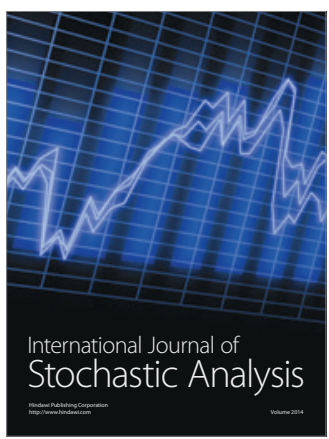

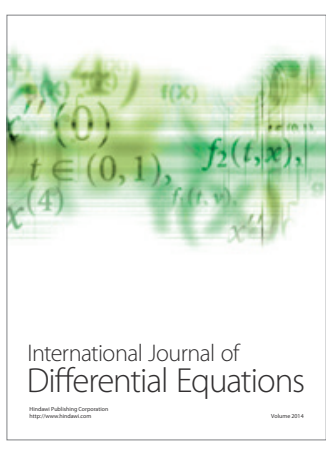
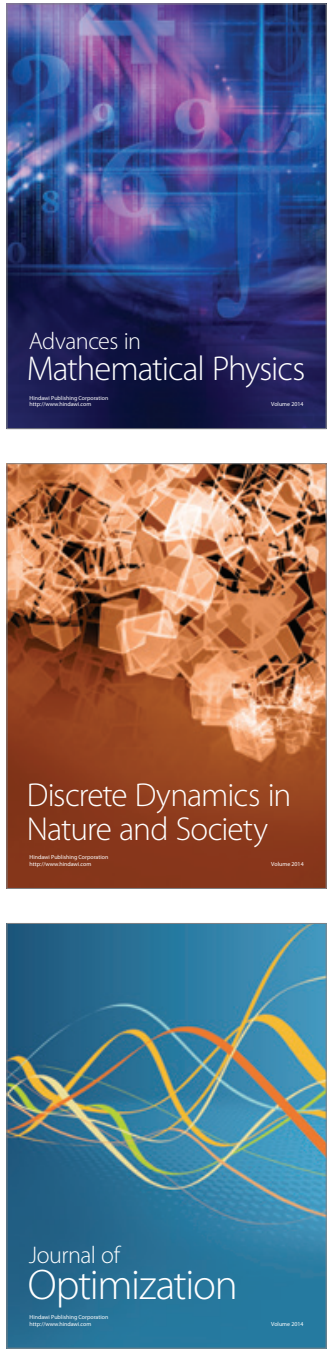